SUSI MARY DE SOUZA FERNANDES

\title{
Efeitos da orientação postural na utilização de mochilas escolares em estudantes do Ensino Fundamental
}

Dissertação apresentada à Faculdade de Medicina da Universidade de São Paulo para obtenção do título de Mestre em Ciências

Área de Concentração: Movimento, Postura e Ação Humana Orientadora: Profa Dra. Raquel Aparecida Casarotto 


\title{
Dados Internacionais de Catalogação na Publicação (CIP)
}

\author{
Preparada pela Biblioteca da
}

Faculdade de Medicina da Universidade de São Paulo

Creprodução autorizada pelo autor

Fernandes, Susi Mary de Souza

Efeitos da orientação postural na utilização de mochilas escolares em estudantes do ensino fundamental / Susi Mary de Souza Fernandes. -- São Paulo, 2007.

Dissertação(mestrado)--Faculdade de Medicina da Universidade de São Paulo. Departamento de Fisioterapia, Fonoaudiologia e Terapia Ocupacional.

Área de concentração: Movimento, Postura e Ação Humana.

Orientadora: Raquel Aparecida Casarotto.

Descritores: 1.Fisioterapia (Especialidade) 2.Prevenção primária 3.Promoção da saúde 4.Crianças 5. Postura 6.Suporte de carga 
"Depois de algum tempo você aprende que verdadeiras amizades continuam a crescer mesmo a longas distâncias, e o que importa não é o que você tem na vida, mas quem você tem na vida." 


\section{AGRADECIMENTOS}

A Raquel Aparecida Casarotto, pela orientação, dedicação e confiança que foram muito além da elaboração e desenvolvimento deste projeto.

A minha amiga Cristina Cabral, pelo incentivo e motivação durante todas as etapas da Pós-Graduação.

Aos amigos Camila Torriani e Carlos Bandeira de Melo Monteiro, pela disponibilidade em colaborar todas as vezes que obstáculos apareceram.

As colegas Amanda Del Cistia, Aline de Almeida Martins e Mellina Strabeli Ricci Armellin, que participaram na execução deste projeto.

A Neuza Maria Anacleto Artéa, diretora do Colégio Nossa Senhora do Carmo pela oportunidade e confiança.

Aos professores, pais e alunos do Colégio Nossa Senhora do Carmo, pela confiança e paciência durante a execução deste trabalho.

Ao amigo Marcos Rennar pelo auxílio fundamental na execução do material gráfico deste estudo.

Aos meus familiares, especialmente Maria José e João Geraldo, pelo incentivo e apoio que me conduziram até aqui.

As minhas filhas, Beatriz e Alice, simplesmente por existirem. 


\section{NORMALIZAÇÃO ADOTADA}

Essa dissertação está de acordo com a as seguintes normas, em vigor no momento desta publicação:

Referências: adaptado do International Commitee of Medical Journals Editors (Vancouver)

Universidade de São Paulo. Faculdade de Medicina. Serviço de Biblioteca e Documentação. Guia de apresentação de dissertações, teses e monografias. Elaborado por Anneliese Carneiro da Cunha, Maria Julia de A. L. Freddi, Maria F. Crestanha, Marinalva de Souza Aragão, Suely Campos Cardoso, Valéria Vilhena. 2P $\mathrm{aP}^{\mathrm{AP}}$ ed. São Paulo: Serviço de Biblioteca e documentação, 2005.

Abreviaturas dos títulos dos periódicos de acordo com List of Journals Indexed in Index Medicus. 


\section{SUMÁRIO}

Lista de Figuras

Lista de Tabelas

Resumo

Summary

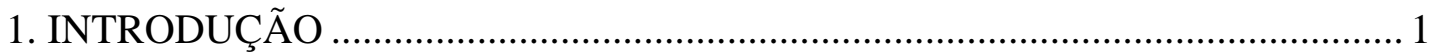

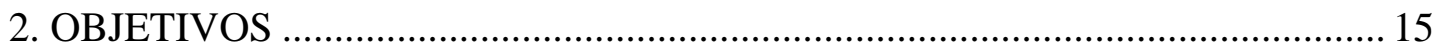

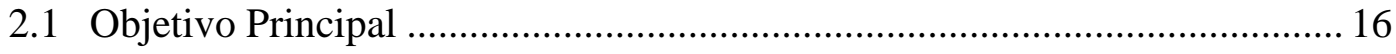

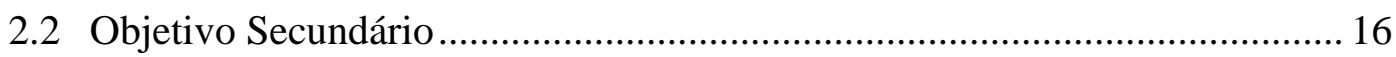

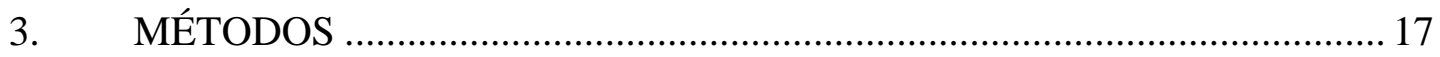

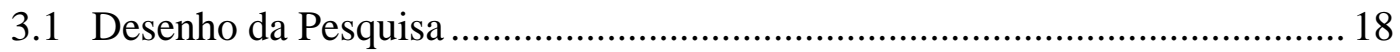

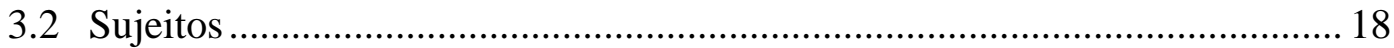

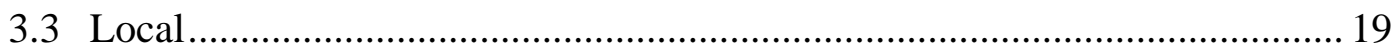

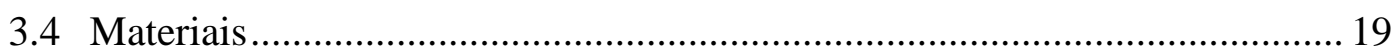

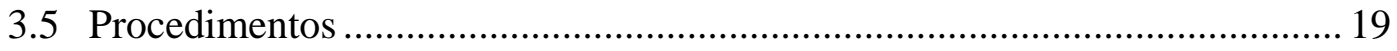

3.5.1 Medida de Avaliação .................................................................. 20

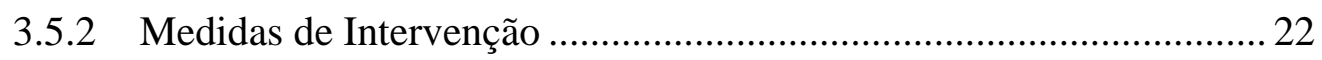

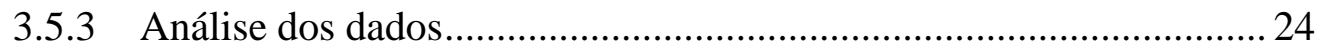

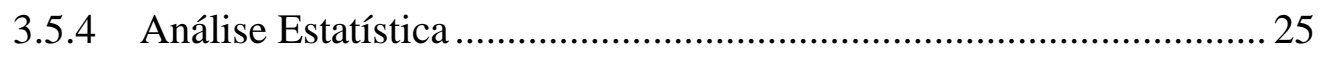

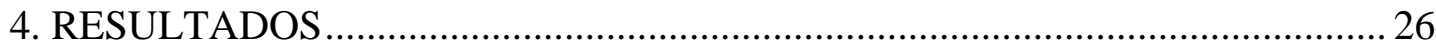

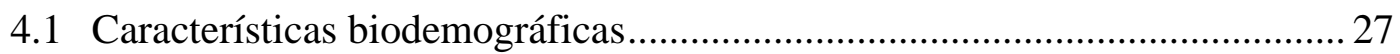

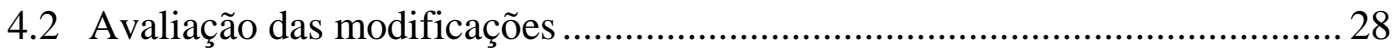

4.2.1 Avaliação modificações peso transportado ......................................... 29

4.2.2 Avaliação adequação no peso das mochilas....................................... 30

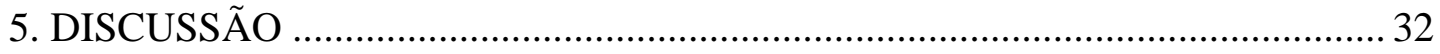

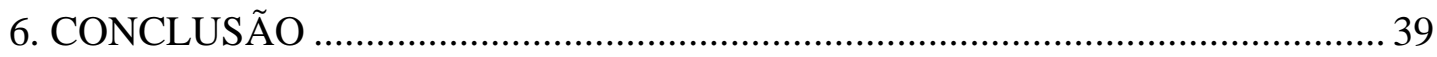

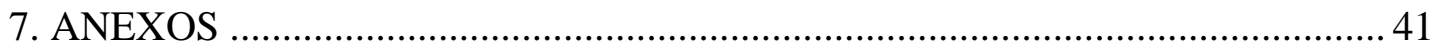

Anexo 1: Submissão ao Comitê de Ética ............................................................. 42

Anexo 2: Registro Ensaios Clínicos.................................................................... 43

Anexo 3: Termo de Consentimento Livre e Esclarecido - Escola .......................... 45

Anexo 4: Termo de Consentimento Livre e Esclarecido ....................................... 47

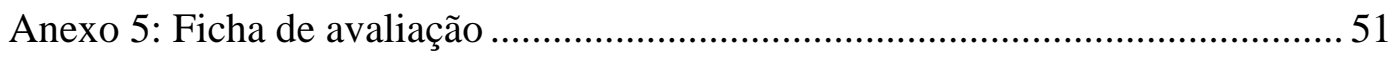

Anexo 6: Folheto de orientações aos pais ou responsáveis.................................. 53

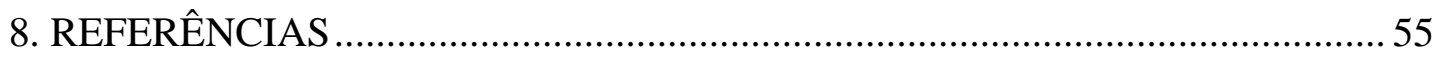




\section{LISTA DE FIGURAS}

Figura 1 - Medida de peso e altura do sujeito

Figura 2 - Medida de peso do equipamento ........................................................ 21

Figura 3 - Sessão Educativa para crianças: conceitos teóricos ................................. 23

Figura 4 - Sessão Educativa para crianças: vivência prática ................................... 23

Figura 5 - Adequação total do peso transportado nas mochilas, considerando a categorização: Adequado (<=10\%), Aceitável (<=15\%) e Inadequado $(>15 \%)(\mathrm{p}<0,001)$ 


\section{LISTA DE TABELAS}

Tabela 1: Variação do peso e altura dos sujeitos .................................................... 27

Tabela 2: Compara a modificação no modelo de mochila...................................... 28

Tabela 3: Compara a modificação no modo de transporte de mochila ..................... 29

Tabela 4: Comparação na modificação do peso absoluto (corporal/mochila) e peso relativo total da amostra.............................................................. 30

Tabela 5: Adequação no peso das mochilas por gênero ........................................ 31 


\section{RESUMO}

Fernandes SMS. Efeitos da orientação postural na utilização de mochilas escolares em estudantes do Ensino Fundamental [dissertação]. São Paulo: Faculdade de Medicina, Universidade de São Paulo; 2007. 61p

OBJETIVO: Avaliar o efeito de sessões educativas no peso, modelo e modo de transportar mochila escolar. MÉTODO: Estudo com 99 crianças, de 7 a 11 anos cursando ensino fundamental em escola particular de São Paulo. Na avaliação foi medido peso do sujeito $(\mathrm{kg})$ e da mochila $(\mathrm{kg})$, tipo e modo de transporte por filmagem pré e pós intervenção. Como medida de intervenção, os sujeitos foram submetidos à sessão educativa que consistiu em orientações sobre coluna vertebral e vivência prática de posturas corretas. Pais e professores também foram orientados. Os sujeitos receberam reforço por 3 meses. RESULTADOS: Os dados foram analisados utilizando testes estatísticos de Igualdade de duas proporções e Wilcoxon, o nível de significância adotado foi de 0,05 (5\%). O tipo de mochila modificou para modelo duas alças $(p=0,046)$, modo de transporte para ombro bilateral $(p=0,047)$. O peso absoluto das mochilas diminuiu 2,66kg $(\mathrm{p}<0,001)$ e o peso relativo diminuiu $7 \%(\mathrm{p}<0,001)$. Na adequação por categoria, o número de sujeitos do grupo adequado e aceitável aumentou, e houve redução do inadequado $(\mathrm{p}<0,001)$. CONCLUSÃO: As sessões educativas modificaram peso, tipo e modo de transporte das mochilas entre os escolares.

DESCRITORES: 1.Fisioterapia (Especialidade) 2.Prevenção primária 3.Promoção da saúde 4.Crianças 5.Postura 6.Suporte de carga 


\section{SUMMARY}

Fernandes SMS. Effects of postural orientation in the use of school backpacks in elementary school students [dissertation]. São Paulo: "Faculdade de Medicina, Universidade de São Paulo”; 2007. 61p.

OBJECTIVE: Evaluate the effect of educational sessions in weight, model and mode of school backpack transport. METHOD: Study of a series of cases with 99 children from seven to ten years of age in a private elementary school in São Paulo. Measured in the evaluation was the weight of the subject $(\mathrm{Kg})$ and backpack $(\mathrm{Kg})$ and type and mode of transport for filming pre and post intervention. They were submitted to an educational session that consisted of orientations on spine and practical use of correct posture; parents and teachers were also guided. The subjects received reinforcement for 3 months. To analyze the final data, it was used two-proportion equality statistic tests and Wilcoxon. The significance level used on the tests was 0,05 (5\%). RESULTS: Backpack type modified for model two straps $(\mathrm{p}=0.046)$, mode of transport for bilateral shoulder $(\mathrm{p}=0.047)$. Absolute weight of the backpacks diminished $2.66 \mathrm{Kg}(\mathrm{p}$ $<0.001)$ and relative weight diminished 7\% ( $<<0.001)$. In adaptation per category, the number of subjects of the appropriate and acceptable groups increased while having a reduction in the inadequate group $(\mathrm{p}<0,001)$. CONCLUSION: Educational sessions modified weight, type and mode of transport of the backpacks among the schoolchildren.

DESCRIPTORS: 1.Physical therapy (Speciality) 2.Prevention primary 3.Health promotion 4.Children 5.Posture 6.Weight bearing 
Nos últimos anos, a saúde escolar tem sido objeto de atenção da comunidade científica, principalmente no que concerne a alterações posturais e dores nas costas entre crianças e adolescentes em idade escolar. Em virtude do grande número de adultos acometidos de doenças da coluna, os pesquisadores atentaram para o fato de que as possíveis causas de tais acometimentos apresentavam relação com a infância e adolescência (Cottalorda et al, 2004).

Harreby et al (1996) aplicaram questionário em 578 indivíduos com idade de 38 anos que tinham participado de estudo conduzido há 25 anos, encontrando número significativo de sujeitos que referiam dor lombar na infância mantida na fase adulta. Concluindo que dor lombar na idade jovem é importante fator de risco na prevalência de dor nas costas quando adulto (Brattberg, 1994; Harreby et al, 1996).

Mirovsky et al (2002) com objetivo de observar se a presença de dor lombar durante a infância predispõe ao quadro de dor na fase adulta, realizaram estudo prospectivo com crianças, no qual 62\% da amostra relataram dor após a maturidade.

Tais achados motivaram estudos epidemiológicos de prevalência de dores nas costas em escolares. No entanto, os resultados não são uniformes com relação à faixa etária.

Balague et al (1996) realizaram experimento para pesquisar a dor não específica na coluna lombar com 615 sujeitos em idade entre 12 e 17 anos, 
encontrando relatos de dores nas costas em $74 \%$ dos sujeitos avaliados, cuja prevalência para dor lombar foi de 69\%.

Em estudo de prevalência para dor nas costas realizado por Kristjansdottir e Rhee (2002) 2.173 escolares com idades entre 11 -12 e 15 -16 anos foram avaliados. A prevalência de dor nas costas ocorrendo ao menos uma vez por semana foi de 20,6\%, com predomínio mais significante nas crianças mais velhas (15 -16 anos) e naquelas que vivem em áreas rurais em relação às que vivem nas cidades.

Também para observar a prevalência de dor lombar em crianças, Newcomer et al (1997) avaliaram 116 crianças entre 10 e 19 anos de idade. Os resultados apontaram história de dor lombar em 51\% da amostra avaliada, com primeiro acometimento acontecendo em média por volta de 12,3 anos de idade. A freqüência de dor lombar no ano anterior à pesquisa foi de 31\% e limitação funcional em $8 \%$ e 7\% das crianças avaliadas, achados observados pelos relatos de atendimento médico devido à dor lombar.

Os estudos de prevalência apresentam dados que variam de 19,7\% a 38,6\% conforme a faixa etária (Balague et al, 1999; Kristjansdottir e Rhee, 2002; Roth-Isigkeit et al, 2004) apontando um crescimento de 1\% na faixa etária de 7 anos para 18\% entre faixa etária de 14 a 16 anos (Taimela et al, 1997; Kristjansdottir e Rhee, 2002).

Troussier et al (1994) aplicaram questionário previamente validado em 1178 escolares de ambos os sexos, no qual 51,2\% da amostra apresentaram prevalência de dor nas costas. A análise estatística revelou correlações positivas entre dor nas costas e variáveis qualitativas, a saber: idade, lesão prévia nas costas, prática de voleibol, sexo feminino e tempo gasto assistindo televisão. Em outro estudo deste mesmo 
grupo, realizado com 972 crianças entre 10 e 14 anos, os resultados apontaram um aumento evidente na prevalência de dor nas costas com a idade, e que as meninas têm maior queixa de dor nas costas em relação aos meninos e que, geralmente, tratava-se de dor lombar. Observaram ainda que a prevalência de escoliose aumentou com a idade, predominantemente em meninas (Troussier et al, 1999).

Achados semelhantes foram descritos por Viry et al (1999) em estudo com 123 escolares com idade média de 14 anos, concluindo que dor nas costas não específica em crianças está quase tão freqüente quanto em adultos, e os fatores de risco são aqueles relacionados à idade específica: sexo feminino; história familiar de dor nas costas (lombar); alto nível de atividade física e permanência prolongada na posição sentada.

A prevalência de dor nas costas não específica é dramaticamente aumentada no período que corresponde à puberdade e ao máximo crescimento linear. Achados revelam aumento de 10\% em pré-adolescentes para 50\% em adolescentes, acometendo meninas entre 12 e 13 anos e meninos entre os 13 e 14 anos de idade (Burton et al, 1999; Leboeuf -Yde et al, 1999; Viry et al, 1999; Sheir -Neiss et al, 2003).

Cottalorda et al (2004) relatam que os estudos apresentam variações para ocorrência de dores nas costas em crianças e adolescentes entre 8 a 84,1\%, de acordo com a população estudada e os critérios avaliados. Descrevem vários fatores causais, como: sexo (maior prevalência em meninas); mal estado geral de saúde; histórico familiar de dores nas costas; perfil psicológico; tempo gasto sentado ou assistindo televisão; aumento da resistência/força dos músculos flexores da coluna vertebral; alta taxa de crescimento; encurtamento dos músculos ísquios tibiais e quadríceps femoral; lesão prévia nas costas; mobilidade fisiológica da coluna 
lombar diminuída; aumento no índice de massa corpórea e idade (maior prevalência de dores nas costas em indivíduos mais velhos); exposição a cargas nas costas (tempo gasto carregando peso) e, por fim, transporte de mochilas muito pesadas (Cottalorda et al, 2004).

Chansirinukor et al (2001) e Mackie et al (2003) referem que as alterações posturais ocorrem quando mochilas pesadas são carregadas, influenciando a postura da coluna cervical e dos ombros, que se projetam para frente.

Em estudo realizado por Sheir-Neiss et al (2003) com 1.126 adolescentes entre 12 e 28 anos de idade, todos os sujeitos da amostra tiveram sua massa corpórea, altura e peso das mochilas anotados. Foram classificados como tendo dor nas costas quando um ou mais itens seguintes fossem relatados durante o mês precedente à coleta; dor no pescoço ou nas costas que interferisse na escola e nas atividades de lazer; dor no pescoço ou nas costas com valor maior ou igual a 2 em escala de 0 a 10; ter consultado médico ou terapeuta devido à dor no pescoço ou nas costas; e dispensa das aulas de educação física ou prática de esportes por motivo de dor no pescoço ou nas costas. Como resultado, do total de 1122 usuários de mochilas, 74,4\% apresentaram dor nas costas, apresentando mal estado geral e funcionamento físico limitado com maior ocorrência de dores generalizadas no corpo.

Na Califórnia, foi realizado estudo com 3.498 estudantes, por Siambanes et al (2004) que mediram o peso de cada estudante comparado ao peso das mochilas e ao trajeto percorrido pelo aluno até a escola em relação à dor nas costas. Concluíram que o peso da mochila classificado como excessivo quando comparado ao peso corporal, influenciava diretamente nas queixas de dor nas costas, e que as meninas apresentavam maior queixa de dor com relação ao trajeto percorrido até a escola. 
Limon et al (2004) encontraram relação significativa entre transporte de mochilas pesadas e dor nas costas. Avaliaram por meio de questionário 10.000 estudantes do ensino fundamental em Israel, os resultados demonstraram que de $30 \%$ a $54 \%$ da amostra transportava peso superior a $15 \%$ do seu peso corporal.

Para Korovessis et al (2004) o transporte e o peso das mochilas não devem ser apenas considerados como fatores desencadeantes de dor nas costas, mas também como fatores de risco para alterações nas curvaturas da coluna no plano sagital e frontal. Em estudo realizado com 3.441 estudantes, encontraram significante relação entre peso das mochilas, alterações posturais, e dores nas costas.

Além das alterações relacionadas à carga da mochila, aspectos sobre o modo de utilização devem ser considerados. Pascoe et al (1997) investigaram o impacto das mochilas em 10 crianças entre 11 e 13 anos de idade usando parâmetros de medida da postura estática e da cinemática mediante a quatro condições: sem mochila, mochila com apoio de uma tira, mochila com apoio de duas tiras e mochila atlética de uma tira. Os resultados mostraram alterações com relação à elevação do ombro e inclinação da coluna vertebral para mochilas com apoio de uma tira e mochilas atléticas. Não houve diferença significativa para alterações nas crianças que utilizaram mochilas com duas alças e aquelas que não utilizaram mochilas.

Cottalorda et al (2004) analisaram o efeito de diferentes modos de transporte de mochilas na cinemática da marcha em crianças, considerando apoio de uma tira em apenas um ombro e apoio de duas tiras nos dois ombros. Observaram que as crianças andavam com passos mais largos, aumento de tempo na fase de apoio simples e duplo apoio, as alterações aumentavam significativamente conforme aumento da carga. Foi também notado desequilíbrio, com aumento de força propulsiva após a fase de 
balanço, para aqueles sujeitos que transportavam mochilas mais pesadas com apoio de uma tira em ombro, fato que induzia à marcha assimétrica. Tais achados não foram notados para transporte de mochila com duas alças nos ombros.

Mackie et al (2003) realizaram estudo comparando 04 tipos de mochilas utilizadas por escolares, dos quais três modelos haviam sido desenvolvidos baseados em conceitos ergonômicos especificamente para utilização escolar. Doze sujeitos foram utilizados na pesquisa. Inicialmente conheceram cada um dos modelos, experimentaram-nos e por último realizaram uma caminhada em um percurso prédeterminado utilizando cada um dos modelos. Os resultados mostraram que as 4 mochilas eram funcionais para caminhada, embora as desenvolvidas ergonomicamente melhorassem o desempenho com relação à mochila não específica. E que os estudantes aceitam bem todos os tipos de mochila e orientações desde que estes colaborem com seu estilo e imagem.

Em 2005, o mesmo grupo de pesquisadores realizou outro experimento simulando os efeitos da carga suportada pelos ombros com relação à tensão e pressões oferecidas pelas diferentes formas de colocação das tiras das mochilas. Um simulador de carga foi utilizado para comparar as forças e pressões das tiras sobre os ombros com relação à velocidade de andar, peso da mochila, distribuição de carga, comprimento da tira no ombro e uso da tira de quadril. Os resultados mostraram que o peso das mochilas aumentava muito a tensão e pressão sobre os ombros, enquanto que o uso de tira no quadril e ajuste no comprimento da tira de ombro diminuía esses efeitos (Mackie et al, 2005).

Dentre os fatores de risco e agravos para dor nas costas destacam-se o transporte e o peso das mochilas utilizadas pelos escolares. Embora a literatura 
científica não tenha ainda identificado o peso crítico por criança acima do qual ela estaria sujeita a dor nas costas (Mackie et al, 2003) bem como a melhor maneira de transporte, vários autores concordam que o peso transportado não deve exceder a 10\% do peso corporal do indivíduo e o transporte deve acontecer com apoio nos dois ombros (Cottalorda et al; Korovessis et al; Limon et al; Siambanes et al, 2004).

Cottalorda et al (2004) referem outras conclusões comuns encontradas na literatura relacionadas ao uso de mochilas escolares, a saber:

- O uso impróprio de mochilas pode resultar em mudanças da postura e da marcha;

- Não há nenhuma evidência de que deformidades estruturais na coluna vertebral podem resultar do uso de mochilas;

- Alguns autores relataram que transportar mochila pesando $20 \%$ do peso corporal esteve significativamente associado a dores nas costas;

- Crianças devem ser orientadas quanto ao transporte de mochilas.

Rateau (2004) considera o uso inadequado de mochilas como um fator importante no desenvolvimento de alterações na mobilidade entre adultos e crianças. Para Cottalorda et al (2004) o excesso de carga das mochilas acima de $10 \%$ do peso corporal resulta numa diminuição do volume corrente dos pulmões.

Em virtude desses achados, justifica-se a elaboração de programas de prevenção para diminuir os riscos de dores nas costas em escolares, originados do transporte e uso inadequados de mochilas escolares. Considerando que para a criança a meta de vida é brincar, qualquer dor que a prive disto é preocupante (Mason, 1999). 
Hábitos posturais incorretos, adotados desde o ensino fundamental, podem gerar alterações irreversíveis nas crianças, considerando que as estruturas que compõem a unidade vertebral (ligamentos e discos) sofrem um processo de degeneração ao longo da vida e não apresentam mecanismos de regeneração (Zapater et al, 2004).

Os programas de treinamentos preventivos têm boa repercussão como forma de melhorar a postura (Feingold e Jacobs, 2002; Goodgold et al, 2002; Goodgold e Nielsen, 2003; Slawta et al, 2006; Geldhof et al, 2007). O European Guidelines for Prevention in Low back pain (2004) também reconhece esses programas como eficientes para melhorar a postura e ainda diminuir a reincidência de dor lombar crônica.

Metanálises apontam evidências de diminuição da dor lombar crônica após programas de treinamento que associam educação e movimento, como por exemplo, o Back School (Maier - Reihle e Harter, 2001; Heymans et al, 2004), que foi proposto originalmente por Mariane Zachrisson - Forsell (1969) e trazido para o Brasil na década de 70, tendo sido desenvolvido como um conjunto de medidas para serem aplicadas com objetivo de prevenir a reincidência de dores nas costas na população trabalhadora. O programa é aplicado em média de 3 a 4 encontros com 1 hora de duração, e associado a conhecimentos de anatomia, fisiologia, biomecânica da coluna, fisiopatologia das dores, orientações ergonômicas e posturais das atividades ocupacionais e de vida diária, além de exercícios de alongamento, força e relaxamento muscular são orientados aos pacientes (Maier - Reihle e Harter, 2001; Heymans et al, 2004; Andrade et al, 2005).

Com objetivo de prevenir as dores nas costas em crianças e adolescentes, este programa vem sendo utilizado em ambiente escolar como Back Schoolchildren (Cardon et al, 2001a,b; 2002a,b). 
Robertson e Lee (1990) realizaram um programa de educação postural enfatizando a postura sentada correta, técnicas específicas para levantamento de carga e prevenção de lesões no esporte entre estudantes de 10 e 12 anos, através de diagramas e práticas de vivência de posicionamento correto e incorreto. Os resultados mostraram que o programa gerou modificações imediatas na adoção da postura correta sentada e no levantamento de carga.

Balague et al (1996) apresentaram um estudo onde 1.716 crianças foram submetidas ao programa educacional de prevenção para dores nas costas. Após um período de 3 anos, as crianças que sofreram intervenção apresentaram um aumento relevante no conhecimento de dores nas costas e uma significativa redução no uso de medicamentos para essas queixas.

Cardon et al (2001a,b; 2002a,b) realizaram estudos com a proposta de investigar os efeitos de um programa de prevenção primária designado BACK SCHOOLCHILDREN. O piloto do estudo teve duração de 6 semanas, em escolares de $4^{\mathrm{a}}$ e $5^{\mathrm{a}}$ série do ensino fundamental. Participaram do estudo 129 crianças divididas aleatoriamente em 2 grupos, o grupo experimental com 36 sujeitos e o grupo controle com 42 sujeitos foram submetidos a avaliações na forma de teste prático e um teste sobre conhecimentos dos cuidados com as costas, antes e depois do programa. A primeira avaliação ocorreu uma semana após iniciado o programa (Cardon et al, 2001a) e 116 sujeitos foram avaliados três meses após término (Cardon et al, 2001b). O programa consistia de seis sessões de sessenta minutos de duração e conhecimentos sobre biomecânica corporal foram ensinados. Os resultados mostraram que os escolares do grupo experimental, que receberam as orientações, 
apresentaram melhor resultado no final de 3 meses comparados ao grupo controle (Cardon et al, 2001b).

Mendez e Gomez-Conesa (2001) realizaram programa de educação postural com objetivo de aperfeiçoar o conhecimento e as habilidades motoras em crianças, e, portanto, diminuir a morbidade de dor nas costas. Participaram deste experimento 106 estudantes da terceira série com idade de 9 anos, divididos em 3 grupos: experimental, controle e placebo. O programa foi executado em três fases: educação, treinamento, aplicação e também envolvia orientação de pais, professores regulares, professores de educação física e estudantes de fisioterapia, com follow - up de 6 e 12 meses. Os resultados mostraram aumento nos conhecimentos sobre anatomia, biomecânica, execução das tarefas sem aumentar a sobrecarga nas costas para o grupo experimental, comparado ao placebo e controle. Ao final do programa, a amostra continuou sendo acompanhada no Serviço de Saúde por um período de 4 anos. O grupo controle apresentou 12,9\% de lombalgias e 4,8\% de escoliose; já o grupo experimental apresentou 3,2\% de lombalgias e nenhum caso de escoliose.

Cardon et al (2002a) confirmam o papel do professor no reforço das orientações posturais. Os resultados encontrados nesse estudo apontaram escores mais alto para o grupo que recebia reforço do professor em comparação com o grupo que não recebia reforço e grupo controle.

Em outro estudo, esse mesmo grupo de pesquisadores utilizou um modelo de circuito. Os estudantes realizavam tarefas de levantamento e transporte de cargas, escolha de conjunto cadeira - mesa adequada a cada estudante e atividades de escrita para avaliação da postura sentada para o grupo experimental, associado a um 
questionário relacionado com prevalência de dor e cuidados com a coluna vertebral, respondido pré e pós-programa de educação postural. Os questionários foram avaliados no período de uma semana e três meses após a intervenção e comparados com o grupo controle. Os resultados do grupo experimental mostraram-se mais altos com relação aos conhecimentos teóricos e práticos confirmados em follow - up de 1 ano ( Cardon et al, 2002b).

Feingold e Jacobs (2002) realizaram estudo de educação com objetivo de melhorar a postura das crianças durante o transporte de mochilas. Participaram do estudo 17 crianças, com idade média de 12,7 anos divididos em grupos de intervenção e controle. Ambos os grupos foram filmados em 4 modos de transportar mochilas e responderam questionário sobre os diferentes modos de transportar cargas, o grupo de intervenção recebeu orientações de modo de transporte adequado. Os resultados revelaram que os membros do grupo de intervenção se beneficiaram da instrução recebida, e $87.5 \%$ desses sujeitos continuaram a utilizar corretamente as mochilas após a intervenção.

Goodgold e Nielsen (2003) realizaram estudo de intervenção baseado em educação, que denominaram Backpack Intelligence, do qual participaram 362 sujeitos da $6^{\mathrm{a}}$ e $7^{\mathrm{a}}$ que receberam programa de educação integrado às aulas de educação física. Os sujeitos foram submetidos à avaliação pré e pós- intervenção, que constava de questionário sobre percepção dos problemas causados pelo transporte inadequado de mochilas. Na avaliação pré-instrução, 44\% relataram incômodo em carregar mochilas e $61 \%$ relataram dois ou mais sinais de que suas mochilas eram excessivamente pesadas. Somente 242 sujeitos concluíram o 
programa e, destes, 42\% mudaram sua maneira de transportar mochilas, e $93 \%$ dos sujeitos melhoraram seus conhecimentos sobre modo de utilizar suas mochilas.

Negrini et al (2004) em estudo de intervenção com objetivo de verificar a eficiência de programa de educação na redução do peso das mochilas, presença de dor entre escolares e para verificar a extensão social do problema, utilizaram 108 escolares de escola rural da Itália, 402 pais e 124 professores. O programa mostrou se efetivo para redução do peso transportado nas mochilas, e também que pais, professores e escolares reconhecem os problemas que podem estar relacionados ao excesso de carga transportado.

Embora ações de orientação e educação em escolares relacionadas ao transporte e uso inadequado da mochila escolar sejam descritas, as evidências com relação aos efeitos desses programas na dor lombar em crianças e o impacto sobre a dor lombar dos adultos são fracos (Burton, 2005).

Após revisão sistemática, o grupo europeu European Guidelines for Prevention in Low Back Pain (2004) categorizou as intervenções de educação postural em escolares como Nível C de evidência - experimentos com um controle aleatorizado ou achados inconsistentes confirmados por múltiplos estudos científicos fracos. Foram encontrados apenas 5 trabalhos que descrevem intervenções baseadas em educação, dos quais 4 tiveram resultados positivos com relação à dor lombar e mudança na utilização de mochilas escolares (modo de transporte e peso). O grupo sugere que novos estudos de educação postural devem ser realizados baseados em informações biomédicas e/ou biomecânicas (Burton, 2005). 
Com base nesses achados estudos de educação postural devem ser realizados, para que medidas de intervenção sejam estabelecidas de forma consensual, a fim de diminuir os agravos das dores nas costas que interferem severamente na qualidade de vida e saúde da população (European Guidelines for Prevention in Low Back Pain, 2004). Em se tratando de crianças, as proporções são ainda maiores, uma vez que as dores privam as experimentações sensoriais tão importantes para o desenvolvimento da postura e controle dos movimentos, colocando o indivíduo precocemente numa situação de limitação motora que, entre outras coisas, comprometem o desempenho escolar (Mason, 1999). 
2. OBJETIVOS 


\subsection{Objetivo Principal}

Avaliar o efeito da orientação postural em estudantes de $1^{\mathrm{a}}$ a $4^{\mathrm{a}}$ série do ensino fundamental de escola particular na cidade de São Paulo.

\subsection{Objetivo Secundário}

Avaliar a modificação no peso, modelo e modo de transporte de mochilas escolares após sessões educativas. 
3. MÉTODOS 


\subsection{Desenho da Pesquisa}

Foi realizado estudo longitudinal de uma série de casos com seguimento de 4 meses, após aprovação do Comitê de Ética para Análise de Pesquisas do Hospital das Clínicas e da Faculdade de Medicina da Universidade de São Paulo, protocolo nº. 669/05 (Anexo 1) e registro no National Institutes of Health - ClinicalTrials.gov $\mathrm{n}^{\mathrm{o}}$ NCT00536354 (Anexo 2).

\subsection{Sujeitos}

Foram selecionados inicialmente 107 estudantes, entre sete e onze anos de idade, cursando da $1^{\mathrm{a}}$ e $4^{\mathrm{a}}$ série do ensino fundamental de escola particular da cidade de São Paulo (Anexo 3) submetidos aos seguintes critérios de inclusão: cursar da primeira à quarta série do ensino fundamental; apresentar idade entre sete e dez anos; estar alfabetizado com habilidade para leitura e escrita; não estar em tratamento médico ou fisioterápico por doença músculo-esquelética e consentir em participar do estudo por meio de Termo de Consentimento Livre e esclarecido (Anexo 4) assinado pelos pais ou responsáveis.

Foram excluídos da pesquisa 08 sujeitos que se ausentaram na segunda avaliação. 


\subsection{Local}

O estudo foi realizado no Colégio Nossa Senhora do Carmo, escola particular de ensino fundamental na cidade de São Paulo (Anexo 3).

\subsection{Materiais}

- Balança Antropométrica Filizola ${ }^{\circledR}$ - modelo 31

- Balança Toledo® - modelo 3400

- Câmera de vídeo Sony® - modelo Handycam vision CCD - TRV65 Hi 8 XR

- Fita para câmera Sony® - modelo CCD - TRV65

- Tripé - modelo 950 Tripod

- Câmera fotográfica digital Cannon®

- Recurso áudio visual de multimídia

\subsection{Procedimentos}

Após inclusão no estudo, os sujeitos foram submetidos à avaliação pré e pós-medida de intervenção, que constou de dados pessoais, registro das medidas de peso e altura dos sujeitos, peso das mochilas, modelo de mochila utilizada, o modo de transporte foi avaliado por filmagem (Anexo 5). 


\subsubsection{Medida de Avaliação}

Modo de Transporte das Mochilas: Como primeira medida de avaliação, a câmera de vídeo foi fixada na portaria principal da escola e os sujeitos sem aviso prévio foram filmados durante cinco dias consecutivos (Cardon et al, 2001a; Feigold e Jacobs, 2002) no momento da chegada. Os dados das filmagens foram categorizados, seguindo quatro modos de transporte descritos por Pascoe et al (1997) e Cottalorda et al (2004) a saber: transporte ombro unilateral, ombro bilateral, mãos e mãos no modelo carrinho.

Modelo de mochilas: Os sujeitos preencheram dados pessoais: identificação; idade (em anos); sexo; série (ano escolar); período (horário que freqüenta a escola) e foram fotografados para facilitar a identificação na filmagem. Os modelos de mochila foram categorizados em modelo uma alça, duas alças e carrinho, seguindo o mesmo adotado no estudo realizado por Mackie et al (2003).

Peso transportado: A balança foi calibrada seguindo especificações do fabricante e os achados após calibração foram conferidos em balança digital de mesa. Os sujeitos foram orientados a subir na balança e tiveram seu peso (kg) e altura $(\mathrm{cm})$ anotados, para determinar a quantidade de peso que poderiam transportar (Figura 1). Em seguida, o peso das mochilas (kg) foi medido na mesma balança (Figura 2). 


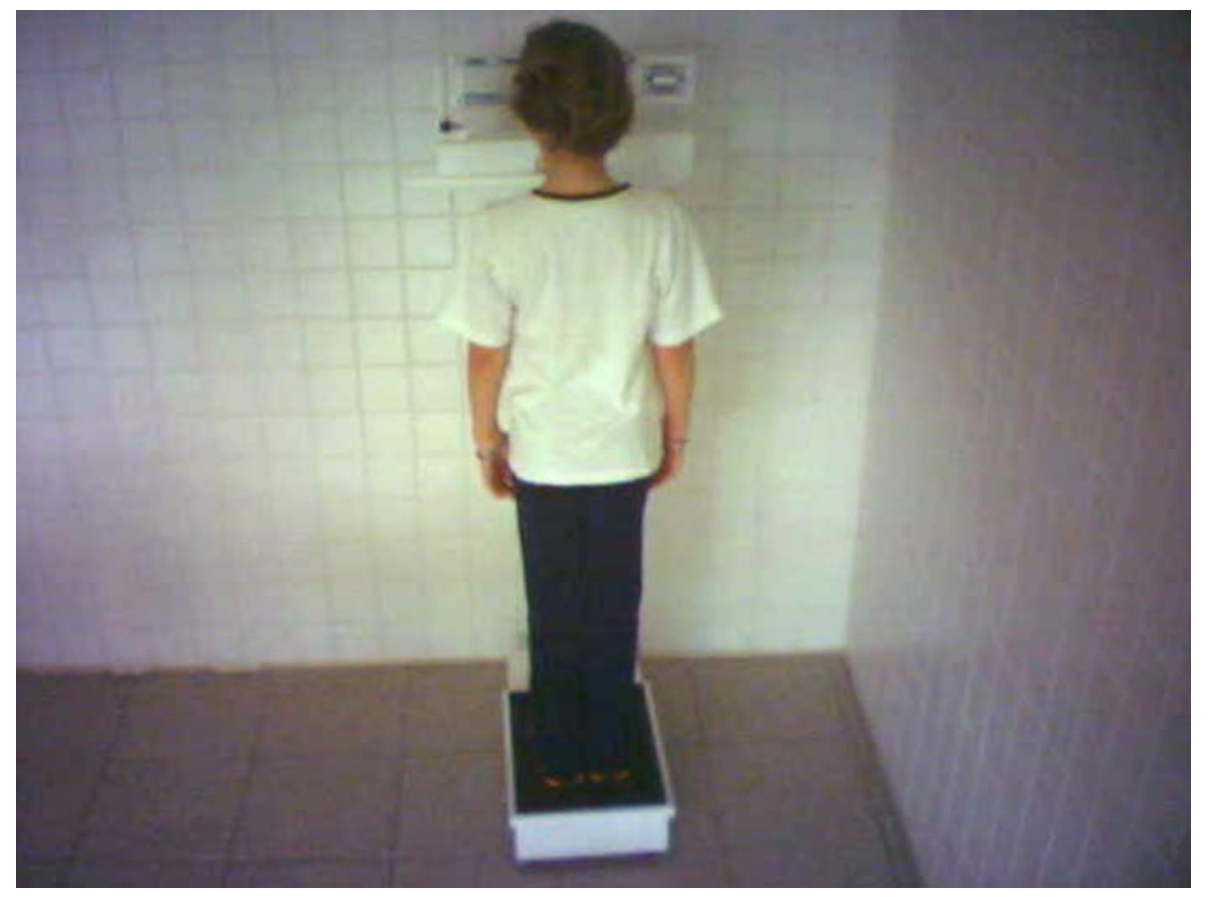

Figura 1 - Medida de peso e altura do sujeito

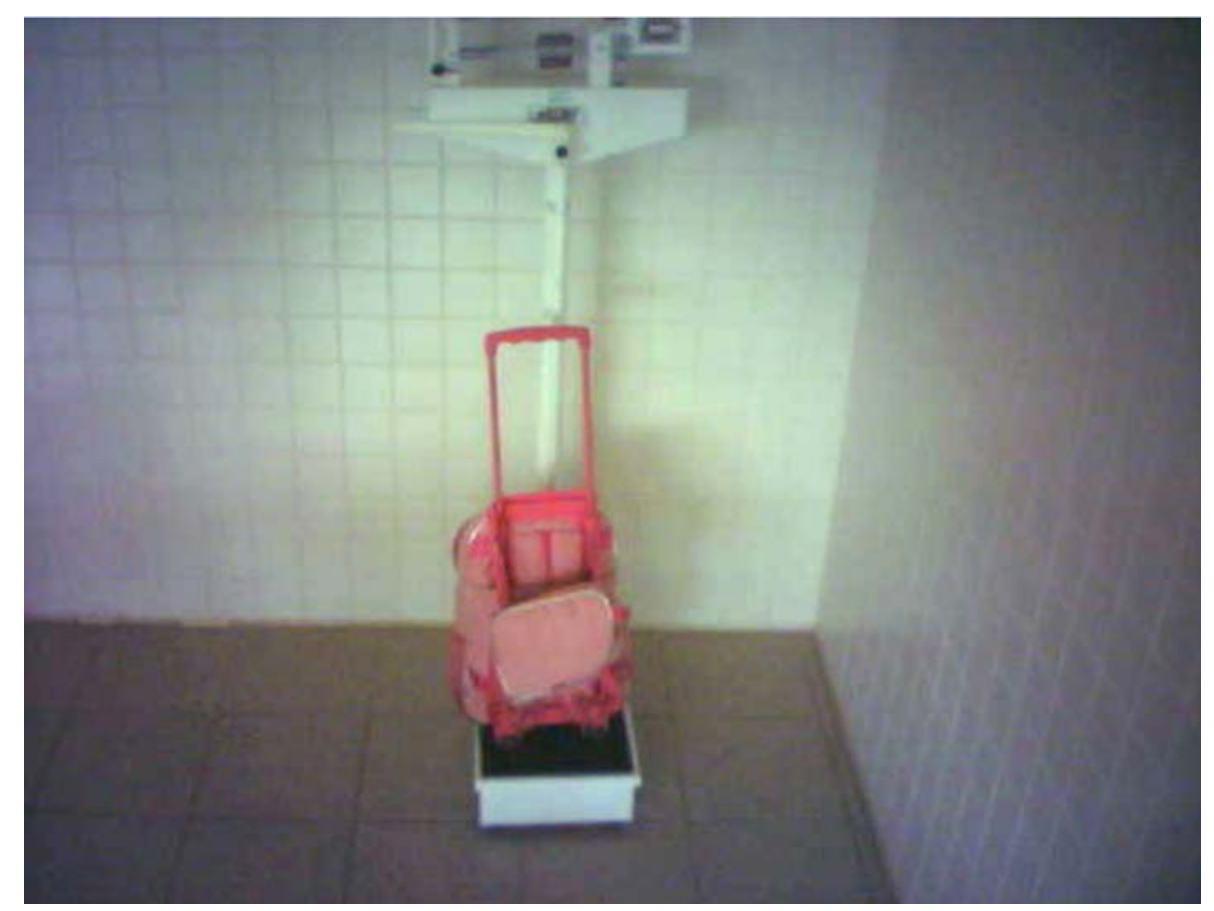

Figura 2 - Medida de peso do equipamento 
Considerando dados da $1^{\mathrm{a}}$ avaliação, os sujeitos foram divididos em três categorias para adequação no peso transportado nas mochilas; a saber: ADEQUADO: peso transportado igual ou menor que $10 \%$ do peso corporal; ACEITÁVEL: peso transportado até 15\% do peso corporal; INADEQUADO: peso transportado superior a 15\% do peso corporal (Mackie et al, 2003; Cottalorda et al, 2004; Korovessis et al, 2004; Limon et al, 2004; Siambanes et al, 2004).

Para orientar pais e professores, o peso do material escolar de uso diário exigido pela escola também foi anotado.

Após um período de quatro meses da avaliação inicial e após intervenção, as crianças foram novamente avaliadas.

\subsubsection{Medidas de Intervenção}

\section{Sessões Educativas}

Após avaliação inicial, foram realizadas três palestras de orientação postural, baseadas no conceito BackSchoolchildren (Cardon et al, 2001a,b; Cardon et al, 2002a). Nas sessões foram desenvolvidos os seguintes conteúdos: conceitos de anatomia, biomecânica e fisiopatologia das lesões de coluna vertebral; orientações sobre excesso de peso, modelo e modo adequado no transporte das mochilas escolares; orientações sobre peso do material de uso diário exigido pela escola e orientações para aquisição de material mais leve, com duração de 60 minutos.

A primeira sessão educativa foi destinada aos pais e/ou responsáveis, a segunda para professores e diretores da escola e a terceira foi destinada aos escolares participantes do estudo. Na sessão destinada às crianças, o conteúdo foi dividido em 
conceitos teóricos (Figura 3) e vivência prática de contração, relaxamento e alongamento muscular (Figura 4); posturas corretas e incorretas nas seguintes situações: 1) em pé: cabeça e tronco eretos, altura dos ombros, braços ao longo do corpo e pés afastados na largura dos ombros; 2) em pé, utilizando mochilas: modelo duas alças com transporte ombro bilateralmente e carga 10\% peso corporal.

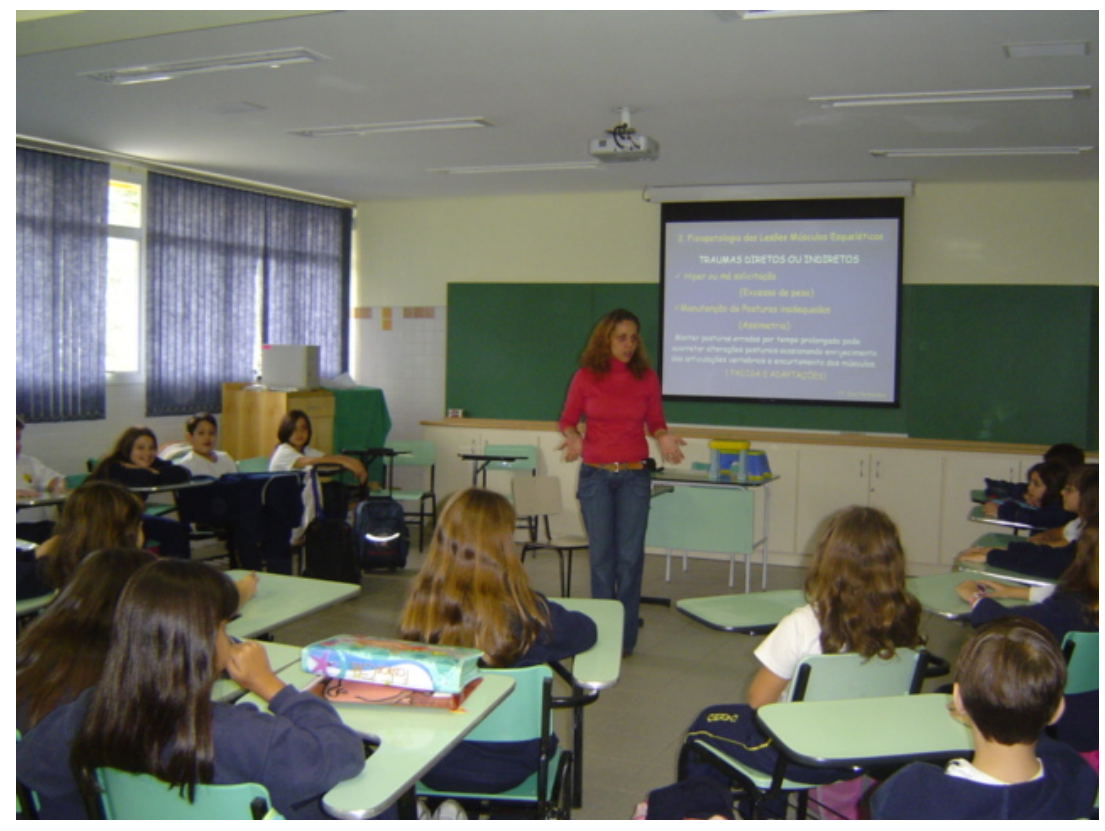

Figura 3 - Sessão Educativa para crianças: conceitos teóricos

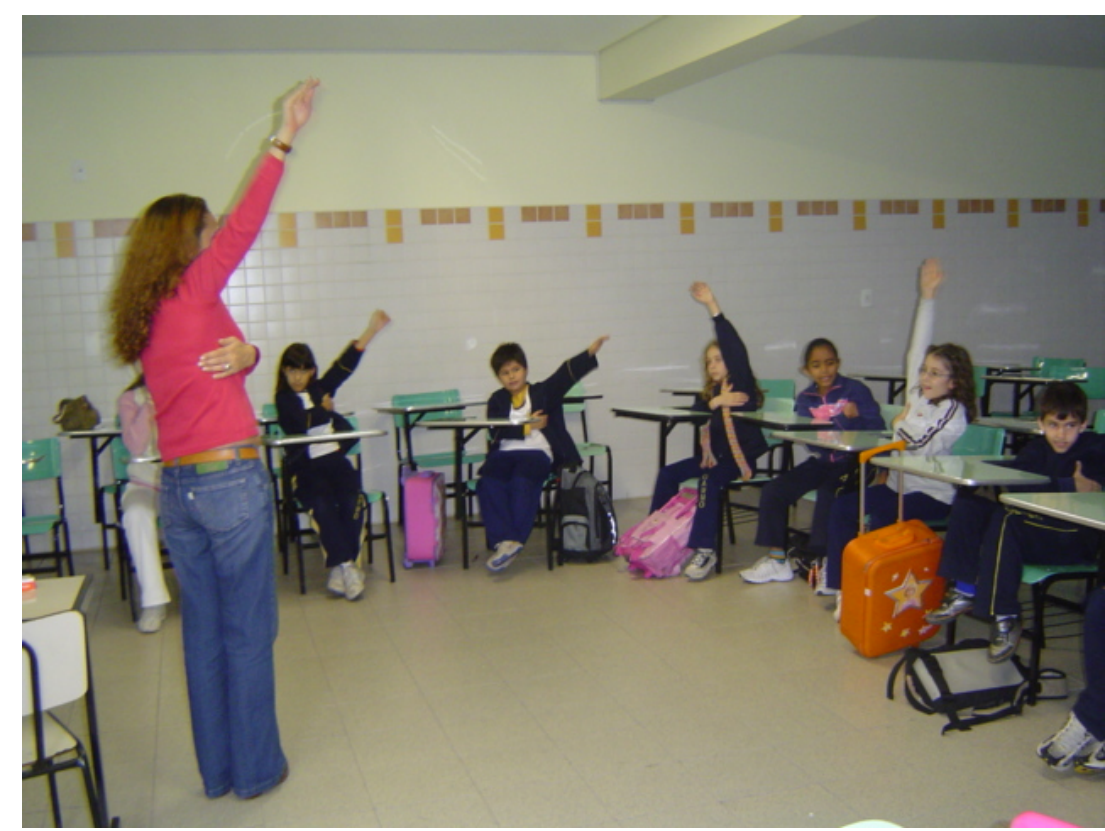

Figura 4 - Sessão Educativa para crianças: vivência prática 


\section{Reforços Mensais}

Após intervenção, as crianças receberam reforços das orientações durante três meses. Nesses encontros, as orientações foram reforçadas por vivências práticas na sala de aula, com duração de 60 minutos. Como reforço para os pais e /ou responsáveis, foi criado folheto tamanho A4 com conteúdo resumido da palestra (Anexo 6) que foi ampliado em cartaz e colocado nas salas de aula e sala dos professores para servir de reforço aos professores e próprios alunos. O conteúdo da palestra foi adicionado em home-page da escola (www.colegiocarmo-sp.com.br) durante seguimento da amostra.

\subsubsection{Análise dos dados}

Os dados analisados nesse estudo são referentes a 99 sujeitos de $1^{\mathrm{a}}$ a $4^{\mathrm{a}}$ série do ensino fundamental, avaliados no período pré-intervenção ( $1^{\text {a }}$ avaliação) e 4 meses após a intervenção ( $2^{\mathrm{a}}$ avaliação).

A modificação no peso das mochilas foi analisada quantitativamente de duas formas:

- peso absoluto (Kg)

- peso relativo: peso do sujeito / peso das mochilas (\%)

Para avaliar qualitativamente a modificação, os sujeitos foram divididos em três categorias, para adequação do peso transportado, considerando dados da $1^{\text {a }}$ avaliação, de tal modo que os resultados foram apresentados seguindo a 
categorização, representada abaixo no quadro 1 ( Mackie et al, 2003; Cottalorda et al,2004; Korovessis et al, 2004; Limon et al,2004; Siambanes et al,2004).

Quadro 1: Categorias para adequação no peso transportado na mochila

\begin{tabular}{|c|c|c|}
\hline ADEQUADO & ACEITÁVEL & INADEQUADO \\
\hline $\begin{array}{c}\text { Peso transportado } \\
\text { menor ou igual a } 10 \% \\
\text { peso corporal do sujeito }\end{array}$ & $\begin{array}{c}\text { Peso transportado } \\
\text { menor ou igual a } 15 \% \\
\text { peso corporal do sujeito }\end{array}$ & $\begin{array}{l}\text { Peso transportado } \\
\text { maior que } 15 \% \text { peso } \\
\text { corporal do sujeito }\end{array}$ \\
\hline
\end{tabular}

\subsubsection{Análise Estatística}

As variáveis qualitativas foram resumidas em freqüências simples e relativas (valores percentuais) foi utilizado o teste estatístico Igualdade de Duas Proporções (Conover,1971; Vieira, 2004). As informações referentes às variáveis quantitativas foram expressas em médias, medianas, desvios-padrão, quartis, coeficiente de variabilidade e intervalo de confiança e utilizado o teste estatístico Wilcoxon (Conover,1971; Vieira, 2004).

O nível de significância adotado foi 0,05 (5\%). Os intervalos de confiança foram construídos com 95\% de confiança estatística e o programa estatístico utilizado foi o SPSS for Windows, versão 11.0. 
4. RESULTADOS 


\subsection{Características biodemográficas}

Dos 99 sujeitos estudados, 48,5\% (n= 48) eram do sexo feminino e $51,5 \%$ ( $\mathrm{n}=51)$ do sexo masculino; 23,2\% $(\mathrm{n}=23)$ cursavam $1^{\mathrm{a}}$ série; $20,2 \%(\mathrm{n}=20) 2^{\mathrm{a}}$ série; 31,3\% (n=31) a $3^{\mathrm{a}}$ série e $25,3 \%(\mathrm{n}=25)$ freqüentavam a $4^{\mathrm{a}}$ série. A idade média na primeira avaliação foi de $8,98 \pm 0,23$ anos.

A tabela 1 demonstra a variação de peso e altura dos sujeitos, podendo-se observar um aumento nos valores de média para altura e diminuição nos valores de média para o peso corporal, com diferença estatisticamente significante $(\mathrm{p}<0,001)$.

Tabela 1: Variação do peso e altura dos sujeitos

\begin{tabular}{|c|c|c|c|c|}
\hline \multirow{2}{*}{ Comparação } & \multicolumn{2}{|c|}{ Altura } & \multicolumn{2}{|c|}{ Peso } \\
\hline & $1^{\text {a }}$ Coleta & $2^{\mathrm{a}}$ Coleta & $1^{\text {a }}$ Coleta & $2^{\mathrm{a}}$ Coleta \\
\hline Média & 1,36 & 1,63 & 36,86 & 35,92 \\
\hline Mediana & 1,35 & 1,39 & 34,7 & 35,1 \\
\hline Desvio Padrão & 0,08 & 2,51 & 8,60 & 9,91 \\
\hline $\mathrm{CV}$ & $6,2 \%$ & $153,7 \%$ & $23,3 \%$ & $27,6 \%$ \\
\hline Q1 & 1,3 & 1,32 & 30,05 & 29,4 \\
\hline Q3 & 1,42 & 1,44 & 42,55 & 42,30 \\
\hline $\mathrm{N}$ & 107 & 99 & 107 & 99 \\
\hline IC & 0,016 & 0,494 & 1,63 & 1,95 \\
\hline p-valor & \multicolumn{2}{|c|}{$<0,001 *$} & \multicolumn{2}{|c|}{$<0,001 *$} \\
\hline
\end{tabular}

* valores estatisticamente significantes 


\subsection{Avaliação das modificações}

A tabela 2 demonstra modificação para o tipo de mochila. Na primeira avaliação, 49,5\% usavam modelo carrinho, seguido do modelo duas alças 46,5\%. $\mathrm{Na}$ segunda avaliação, verificou-se aumento do número de sujeitos que utilizavam mochila duas alças para 60,6\% (p=0,046) e uma redução estatisticamente significante para os sujeitos que utilizavam carrinho $33,3 \%(\mathrm{p}=0,021)$.

Tabela 2: Compara a modificação no modelo de mochila

\begin{tabular}{cccccc}
\hline \multirow{2}{*}{ Modelo mochila } & \multicolumn{2}{c}{ Pré-intervenção } & \multicolumn{2}{c}{ Pós-intervenção } & \multirow{2}{*}{ p-valor } \\
\cline { 2 - 4 } & Qtde & $\%$ & Qtde & $\%$ & \\
\hline Uma Alça & 4 & $4,0 \%$ & 6 & $6,1 \%$ & 0,234 \\
\hline Duas Alças & 46 & $46,5 \%$ & 60 & $60,6 \%$ & $\mathbf{0 , 0 4 6} *$ \\
\hline Carrinho & 49 & $49,5 \%$ & 33 & $33,3 \%$ & $\mathbf{0 , 0 2 1} *$ \\
\hline
\end{tabular}

* valores estatisticamente significantes

No modo de transporte, a tabela 3 demonstra o aumento de $41,4 \%$ para $55,6 \%(p=0,047)$ para transporte ombro bilateral, para transporte em mãos foi observado redução de $5,1 \%$ para $0,0 \%(p=0,024)$. Notou-se diminuição no número de sujeitos que transportavam mochilas de carrinho na mão de 44,4\% para 32,2\% $(p=0,08)$ e para transporte ombro unilateral os resultados apontaram aumento de 9,1\% para 12,1\% ( $\mathrm{p}=0,489)$, porém nessas situações os resultados não apresentaram relevância estatística. 
Tabela 3: Compara a modificação no modo de transporte de mochila

\begin{tabular}{cccccc}
\hline \multirow{2}{*}{ Transporte } & \multicolumn{2}{c}{ Pré- intervenção } & \multicolumn{2}{c}{ Pós-intervenção } & \multirow{2}{*}{ p-valor } \\
\cline { 2 - 5 } & Qtde & $\mathbf{\%}$ & Qtde & $\mathbf{\%}$ & \\
\hline Ombro unilateral & 9 & $9,1 \%$ & 12 & $12,1 \%$ & 0,489 \\
\hline Ombro bilateral & 41 & $41,4 \%$ & 55 & $55,6 \%$ & $\mathbf{0 , 0 4 7} *$ \\
\hline Mão D + E & 5 & $5,1 \%$ & 0 & $0,0 \%$ & $\mathbf{0 , 0 2 4} *$ \\
\hline $\begin{array}{c}\text { Mão mochila } \\
\text { carrinho }\end{array}$ & 44 & $44,4 \%$ & 32 & $32,3 \%$ & 0,080 \\
\hline
\end{tabular}

* valores estatisticamente significantes

\subsubsection{Avaliação modificações peso transportado}

A tabela 4 demonstra a modificação no peso das mochilas, apontando diferença estatisticamente significante entre as duas avaliações para todas as variáveis avaliadas $(\mathrm{p}<0,001)$. Houve uma redução significativa $(\mathrm{p}<0,001)$ quanto ao peso absoluto da mochila. A diferença média foi de 2,66 kg (I.C. (95\%) = [2,36; 2,96]). Houve, também, uma redução significativa $(\mathrm{p}<0,001)$ no peso relativo da mochila de $19,3 \%$ para $12,3 \%$, sendo que a diferença média foi de $7 \%$ (I.C. $(95 \%)=[6,1 ; 7,8])$. 
Tabela 4: Comparação na modificação do peso absoluto (corporal/mochila) e peso relativo total da amostra

\begin{tabular}{ccccccc}
\hline \multirow{2}{*}{ Peso } & \multicolumn{2}{c}{ Corporal Absoluto (Kg) } & \multicolumn{2}{c}{ Mochila Absoluto(Kg) } & \multicolumn{2}{c}{ Mochila Relativo(\%) } \\
\cline { 2 - 7 } & $\begin{array}{c}\text { Pré- } \\
\text { intervenção }\end{array}$ & $\begin{array}{c}\text { Pós- } \\
\text { intervenção }\end{array}$ & $\begin{array}{c}\text { Pré- } \\
\text { intervenção }\end{array}$ & $\begin{array}{c}\text { Pós- } \\
\text { intervenção }\end{array}$ & $\begin{array}{c}\text { Pré- } \\
\text { intervenção }\end{array}$ & $\begin{array}{c}\text { Pós- } \\
\text { intervenção }\end{array}$ \\
\hline Média & 37,26 & 36,17 & 6,92 & 4,26 & $\mathbf{1 9 , 3 \%}$ & $\mathbf{1 2 , 3 \%}$ \\
\hline Mediana & 36,8 & 35,1 & 6,9 & 4,3 & $19,0 \%$ & $12,3 \%$ \\
\hline DP & 8,69 & 9,32 & 1,48 & 1,46 & $5,0 \%$ & $4,6 \%$ \\
\hline CV & $23,3 \%$ & $25,8 \%$ & $21,5 \%$ & $34,2 \%$ & $25,8 \%$ & $37,5 \%$ \\
\hline Q1 & 30,85 & 29,4 & 5,925 & 3,3 & $15,8 \%$ & $9,4 \%$ \\
\hline Q3 & 42,6 & 42,3 & 7,85 & 5 & $21,7 \%$ & $14,8 \%$ \\
\hline N & 99 & 99 & 99 & 99 & 99 & 99 \\
\hline IC & 1,71 & 1,84 & 0,29 & 0,29 & $1,0 \%$ & $0,9 \%$ \\
\hline p-valor & $<\mathbf{0 , 0 0 1 *}$ & & $<\mathbf{0 , 0 0 1 *}$ & & $<\mathbf{0 , 0 0 1 *}$ \\
\hline
\end{tabular}

* valores estatisticamente significantes

\subsubsection{Avaliação adequação no peso das mochilas}

Os resultados para adequação revelaram diferença estatisticamente significante $\left(p^{<0,001)}\right.$ entre as duas avaliações em todas as categorias, apontando um aumento percentual dos sujeitos classificados como adequados de 3,0\% para 30,3\% e uma redução na porcentagem de sujeitos classificados como inadequados de 82,8\% para 24,2\%. Um aumento significativo no percentual de sujeitos classificados como aceitável de 14,1\% para 45,5\% também foi notado, conforme demonstra figura 5. 


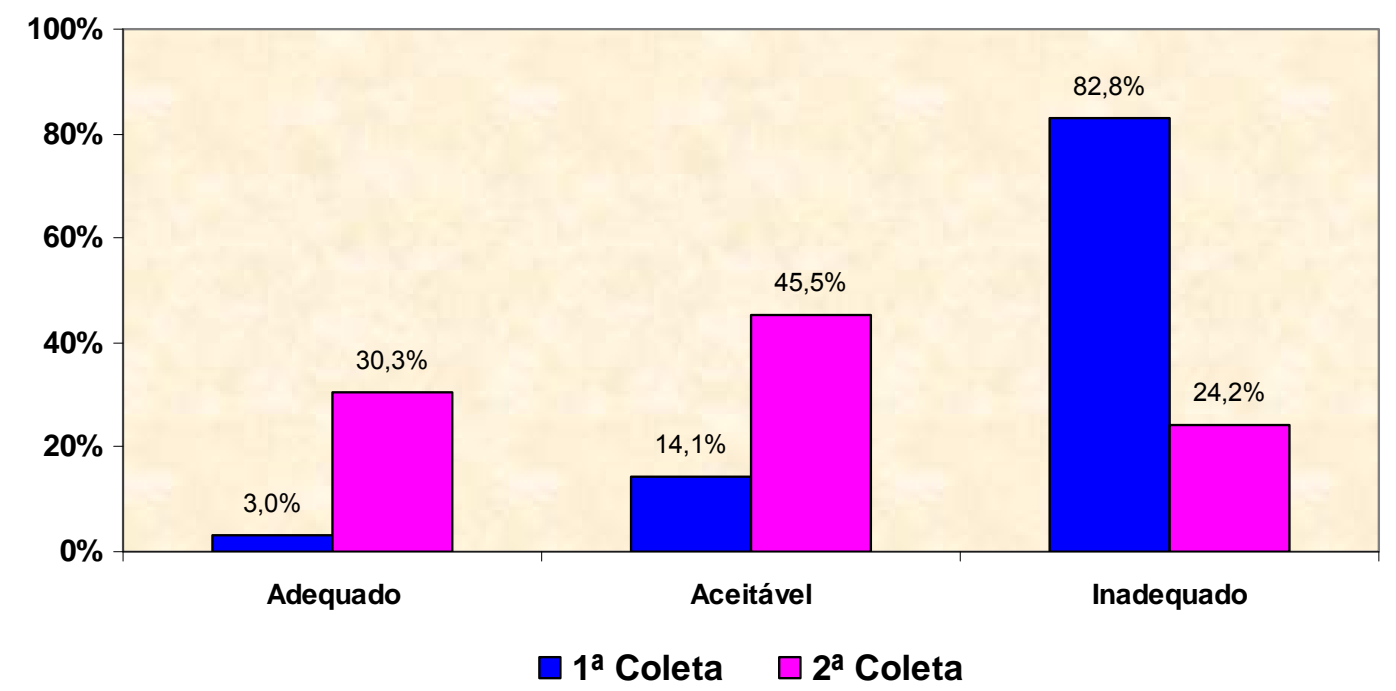

Figura 5 - Adequação total do peso transportado nas mochilas, considerando a categorização: Adequado (<=10\%), Aceitável (<=15\%) e Inadequado $(>15 \%)(\mathrm{p}<0,001)$

A tabela 5 ilustra a avaliação da adequação no peso das mochilas por gênero. Os resultados demonstram modificação estatisticamente significativa nos dois grupos para todas as categorias.

Tabela 5: Adequação no peso das mochilas por gênero

\begin{tabular}{|c|c|c|c|c|c|c|}
\hline \multirow{2}{*}{\multicolumn{2}{|c|}{ Sexo }} & \multicolumn{2}{|c|}{$1^{\text {a }}$ Coleta } & \multicolumn{2}{|c|}{$2^{\mathrm{a}}$ Coleta } & \multirow{2}{*}{ p-valor } \\
\hline & & Qtde & $\%$ & Qtde & $\%$ & \\
\hline \multirow{3}{*}{ Feminino } & Aceitável & 7 & $14,6 \%$ & 25 & $52,1 \%$ & $<0,001^{*}$ \\
\hline & Adequado & 0 & $0,0 \%$ & 14 & $29,2 \%$ & $<0,001 *$ \\
\hline & Inadequado & 41 & $85,4 \%$ & 9 & $18,8 \%$ & $<0,001^{*}$ \\
\hline \multirow{3}{*}{ Masculino } & Aceitável & 7 & $13,7 \%$ & 20 & $39,2 \%$ & $0,004 *$ \\
\hline & Adequado & 3 & $5,9 \%$ & 16 & $31,4 \%$ & $<0,001 *$ \\
\hline & Inadequado & 41 & $80,4 \%$ & 15 & $29,4 \%$ & $<0,001 *$ \\
\hline
\end{tabular}

*valores estatisticamente significantes 
5. DISCUSSÃO 
Os achados deste estudo revelaram mudanças significativas na utilização de mochilas pelos escolares comparando avaliações pré e pós-intervenção, tanto para o tipo de mochila utilizada quanto para modo de transporte e, principalmente, no peso transportado nas mochilas $(\mathrm{p}<0,001)$, demonstrando a eficiência do modelo de intervenção baseado em educação e corroboram com estudos anteriores.

Feingold e Jacobs (2002) avaliaram os efeitos de um programa de educação sobre utilização de mochilas, e encontraram para os sujeitos do grupo de intervenção maior aderência $(87,5 \%)$ às orientações recebidas quando comparados ao controle. Goodgold e Nielsen (2003) em intervenção com 242 sujeitos, encontraram mudanças em 52\% dos sujeitos avaliados no modo de utilização das mochilas; 93\% dos sujeitos melhoraram seus conhecimentos sobre modo de utilizar suas mochilas.

Embora os estudos realizados apresentem diferenças metodológicas na idade e número de sujeitos, duração das orientações recebidas e modelos de intervenção diferentes, suas conclusões demonstram uma aderência satisfatória a programas de educação entre os escolares.

Programas de mudanças de hábitos apresentam aderência satisfatória em outras áreas de atenção a saúde. Slawta et al (2006) realizaram estudo de intervenção com crianças baseado em educação para estilo de vida e sobrepeso com duração de 12 semanas. Os resultados sugerem que programas de promoção à saúde podem ser bem recebidos por crianças e podem promover mudanças em hábitos alimentares e 
estilo de vida diminuindo o sobrepeso em crianças e o aparecimento de doenças, principalmente aquelas relacionadas ao estilo de vida do adulto.

As modificações no tipo de mochila (tabela 2) e modo de transporte (Tabela 3) estão relacionadas às orientações recebidas na sessão educativa que enfatizou o conforto e a simetria corporal no transporte de carga, sendo destacada a utilização de mochila modelo duas alças transportadas em ombros bilateralmente (Mackie et al, 2003; Korovessis et al, 2004; Limon et al, 2004; Siambanes et al, 2004).

A ênfase nessa orientação se deve aos achados da $1^{\text {a }}$ avaliação. Foram encontradas mochilas modelo carrinho com peso superior a $10 \mathrm{~kg}$, apesar do material de uso diário exigido pela escola não ultrapassar 1,5 kg (apostila, agenda escolar e estojo). Notou-se que o excesso de carga transportado era derivado dos modelos de carrinho utilizados, que apresentavam peso entre 5 a $7 \mathrm{~kg}$ quando vazios. As mochilas modelo duas alças não ultrapassavam o peso de $1 \mathrm{~kg}$. Durante a filmagem observou-se que as crianças, para acessarem a sala de aula, tinham que utilizar escadas e o modelo carrinho gerava sobrecarga.

Os sujeitos, os pais ou responsáveis foram orientados na sessão educativa sobre o excesso de carga gerada pela estrutura do modelo de carrinho, fato esse que pode justificar a troca no modelo da $1^{\mathrm{a}}$ para $2^{\mathrm{a}}$ avaliação. No entanto, a adesão dos pais à sessão educativa foi pequena, somente cinco pais estiveram presentes. Estudos de Cardon et al (2002b) e Mendez e Gómez-Conesa (2001) sugerem a participação dos pais como importante reforço nas orientações recebidas. Devido à baixa adesão, decidiu-se, nesse estudo, transformar o conteúdo da palestra em folheto informativo (Anexo 6) e inseri-lo na home-page da escola durante o período de seguimento da amostra. 
No modo de transporte, os resultados demonstraram modificação estatisticamente relevante para o uso nos ombros bilateralmente, observados na tabela 3. Um achado interessante neste estudo refere-se às crianças da $4^{\mathrm{a}}$ série que não aderiram ao uso de mochilas nos ombros, porém passaram a utilizar bolsas pequenas e fichário junto ao corpo, aderindo ao conceito de simetria corporal e transporte de pouco peso.

Esses achados podem ser justificados por estudo de Mackie at al (2003) comparando a utilização de diferentes tipos de mochilas por adolescentes. Em suas conclusões referem que a aceitação de um modelo e modo de transporte de mochilas está relacionada mais com imagem e estilo do adolescente do que com a função e condição física.

Os resultados para modificação no peso transportado nas mochilas revelaram diferença estatisticamente significante para todas as variáveis avaliadas $(\mathrm{p}<0,001)$. Embora o peso das mochilas tenha apresentado diminuição média de 2,66 kg, os valores de peso corporal também diminuíram, conforme tabela 1, que demonstra aumento na altura e diminuição no peso dos sujeitos avaliados $(\mathrm{p}<0,001)$.

Apesar de esperado que as crianças aumentassem de altura, considerando o período de follow-up, outro fator que pode justificar a diminuição no peso corporal das crianças, está relacionado às diferentes estações do ano em que foram realizadas as duas avaliações. A primeira avaliação aconteceu no inverno e a segunda avaliação foi realizada no verão, período em que as crianças utilizam menor quantidade de roupas.

Embora tais achados para diminuição no peso corporal das crianças possam ser justificados, estes poderiam gerar interferência na análise de modificação para 
peso transportado na mochila. Deste modo, optou-se por confirmar os achados para peso transportado nas mochilas pela variável peso relativo, que representa a relação entre peso corporal do sujeito dividida pelo peso das mochilas. A tabela 4 demonstra esses resultados, observando os valores de média, nota-se que também houve diminuição no peso relativo(p<0,001).

Outros estudos de intervenção encontraram resultados semelhantes para redução do peso transportado nas mochilas (Mendez e Gómez-Conesa, 2001; Cardon et al, 2001a e 2002b; Feingold e Jacobs, 2002; Negrini et al, 2002;Goodgold e Nielsen, 2003; Skaggs et al 2006).

Mackie et al (2003) relataram que o peso crítico transportado por criança acima do qual ela estaria sujeita à dor nas costas não foi ainda identificado, bem como a melhor maneira de transporte. Vários autores concordam que o peso transportado não deve exceder a $10 \%$ do peso corporal do indivíduo (Cottalorda et al, 2004; Korovessis et al, 2004; Limon et al,2004; Siambanes et al, 2004). No entanto, os estudos que relacionam dor nas costas ao peso das mochilas em escolares encontraram pesos variando entre 10 até $20 \%$ do peso corporal. Os achados de dor são normalmente relacionados a cargas superiores a 15\% do peso corporal (Cottalorda et al, 2004; Korovessis et al, 2004; Limon et al, 2004; Siambanes et al, 2004). Alguns autores relataram que transportar mochila pesando $20 \%$ do peso corporal esteve significativamente associado a dores nas costas (Watson et al, 2003; Cottalorda et al, 2004; Limon et al, 2004; Siambanes et al, 2004).

Neste estudo, optou-se por categorizar os achados para peso das mochilas considerando a relação peso transportado e presença de dor descrito na literatura. A modificação mais acentuada ocorreu no grupo inadequado, com redução de 58,6\%, 
mostrando que o programa proposto foi efetivo na diminuição de peso considerado crítico para transporte. A Figura 5 demonstra o aumento no número de crianças nas categorias adequado e aceitável.

A tabela 5 demonstra que não houve diferença na modificação por gênero. Em ambos os grupos a migração mais acentuada aconteceu no grupo inadequado ( $p<0,001)$, apesar das meninas apresentarem valores percentuais maiores $66,6 \%$ de redução em comparação com a redução dos meninos que foi de 51,0\%.

A redução maior no peso transportado entre as meninas pode ser justificada por estudos de prevalência que apontam maior freqüência de dor nas costas e transporte excessivo de carga entre as meninas (Troussier et al,1994; Viry at al, 1999; Burton,1999; Leboeuf -Yde et al, 1999; Sheir -Ness et al,2003; Cottalorda,2004).

Os resultados para utilização de mochilas apóiam-se nos dados da Secretaria da Saúde do Brasil. Que registrou no Censo Escolar 2000, a existência de 181.504 escolas destinadas ao ensino fundamental e reconhecem a faixa etária como privilegiada para formação de valores e hábitos favoráveis à saúde e a necessidade de desenvolver medidas educativas integradas e coesas para essa população, de modo que alcance sucesso e impacto (Ministério Saúde, 2002).

Alguns autores sugerem que outras medidas devem ser incorporadas às sessões educativas. Negrini et al (2004) inferem que medida de educação não é a única solução para a diminuição no excesso de carga transportada pelas crianças, e que o limite seguro de carga transportada por criança ainda não foi estabelecido. Skaggs et al (2006) sugerem que além das medidas de orientação sobre excesso de carga transportada pelas crianças, as escolas deveriam ter armários para depósito do material escolar. 
Baseado nessas informações e nos achados deste estudo sugere-se que novos estudos de educação postural sejam realizados utilizando grupo controle, período de follow-up maior, avaliação da participação dos pais, professores e diretores das escolas, e a relação entre peso transportado e presença de dor sejam avaliados. 
Os achados deste estudo revelaram que medidas de intervenção baseadas em orientação postural promoveram mudanças significativas nos hábitos referentes à utilização de mochilas, principalmente no peso transportado e que escolares tem boa aceitação a programas de educação. 
7. ANEXOS 


\section{Anexo 1: Submissão ao Comitê de Ética}
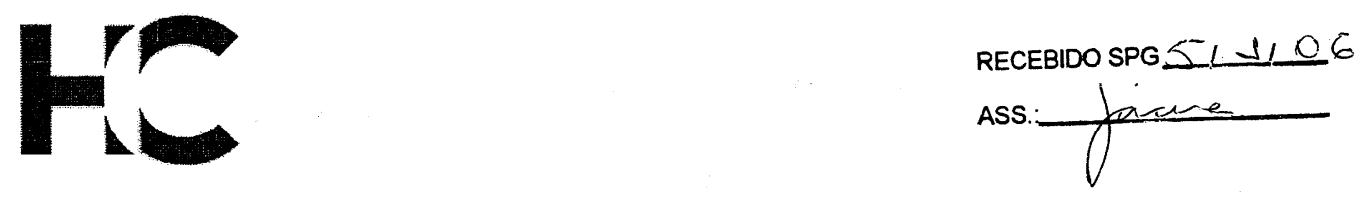

\section{APROVAÇÃO}

A Comissão de Ética para Análise de Projetos de Pesquisa - CAPPesq da Diretoria Clínica do Hospital das Clínicas e da Faculdade de Medicina da Universidade de São Paulo, em sessão de 14.12.05, APROVOU o Protocolo de Pesquisa $n^{\circ}$ 669/05, intitulado: "Efeitos da orientação postural na utilização de mochilas escolares em estudantes do ensino fundamental." apresentado pelo Departamento de Área Fisiopatologia Experimental, inclusive o Termo de Consentimento Livre e Esclarecido.

Cabe ao pesquisador elaborar e apresentar à CAPPesq, os relatórios parciais e final sobre a pesquisa (Resolução do Conselho Nacional de Saúde $n^{\circ}$ 196, de 10.10.1996, inciso IX. 2, letra "c")

Pesquisador(a) Responsável: Sra. Raquel Aparecida Casarotto

Pesquisador (a) Executante: Sra. Susi Mary de Souza Fernandes

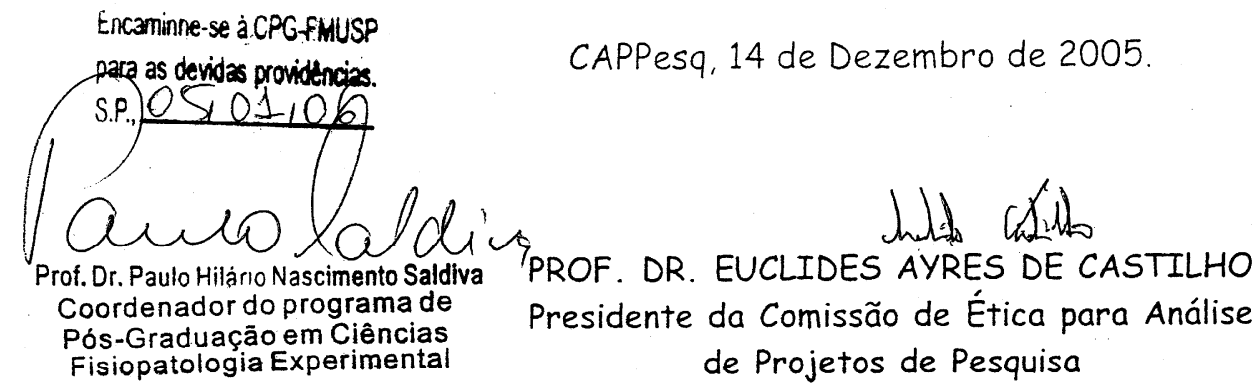

\footnotetext{
Comissõo de Éticg análise de Projetos de Pesquisa do HCFMUSP e da FMUSP Diretoria Clínica do Hospitaladess Clínicas da Faculdade de Medicina da Universidade de São Paulo Rua Ovidio Pires de Caimpos. 225, $5^{\circ}$ andar - CEP 05403010 - São Paulo - SP Fone: 011 - 30696442 fax: 011 - 3069:6492 - e-mail : cappesq@hcnet.usp.br / secretariacappesq@hcnet.usp.br
} 


\section{Anexo 2: Registro Ensaios Clínicos}

\section{ClinicalTrials.gov Protocol Registration System}

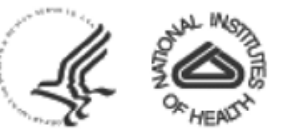

\section{Protocol Registration Receipt}

2007-09-26

\section{Postural Orientation In The Use Of School Backpacks}

This study has been completed.

\begin{tabular}{|r|l|}
\hline $\begin{array}{r}\text { Sponsors and } \\
\text { Collaborators: }\end{array}$ & University of Sao Paulo \\
\hline Information provided by: & University of Sao Paulo \\
\hline ClinicalTrials.gov Identifier: & NCT00536354 \\
\hline
\end{tabular}

\section{Purpose}

This study will examine the effects of postural orientation in the use of school backpacks among elementary school students.

\begin{tabular}{|l|l|l|}
\hline Condition & Intervention & Phase \\
\hline $\begin{array}{l}\text { Backpain } \\
\text { Prevention } \\
\text { Physical Therapy }\end{array}$ & Postural Orientation & Phase 0 \\
\hline
\end{tabular}

Study Type: Interventional

Study Design: Prevention, Open Label, Single Group Assignment

Official Title: Effects Of Postural Orientation In The Use Of School Backpacks In Elementary School Students

Further Study Details:

Study Start: 2005-08; Study Completion: 2005-12 
- Eligibility

Ages Eligible for Study: 7 Years - 10 Years, Genders Eligible for Study: Both Criteria

Inclusion Criteria:

- Children from seven to ten years of age. Studing in private elementary school.

\section{Location and Contact Information}

Brazil, São Paulo

University of São Paulo, São Paulo, São Paulo, 05360-160, Brazil

University of São Paulo, São Paulo, São Paulo, 05360-160, Brazil

Study chairs or principal investigators

Susi MS Fernandes, Master, Principal Investigator

University of São Paulo

\section{More Information}

Study ID Numbers SFernandes

NLM Identifier NCT00536354

Health Authority: Brazil: Committee of Ethics in Research 


\title{
Anexo 3: Termo de Consentimento Livre e Esclarecido - Escola
}

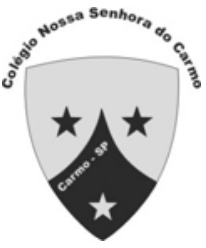 \\ COLÉGIO NOSSA SENHORA DO CARMO - SP \\ Irmãs Carmelitas da Divina Providência \\ Rua Ministro Jesuíno Cardoso, 360 - Itaim Bibi \\ Tel. (11) 3845-1385 - 3845-1770 - Fax: 3846-6584 \\ SÃO PAULO / SP
}

\section{TERMO DE CONSENTIMENTO}

O Colégio Nossa Senhora do Carmo, situado a Rua Ministro Jesuino Cardoso, 360, Itaim-Bibi, São Paulo, capital, através da sua representante legal, autoriza a realização da pesquisa: Efeito da orientação postural na utilização de mochilas escolares em estudantes do ensino fundamental ; com data de início prevista para Agosto/2005 e término em Dezembro/2005; proposta pela Fisioterapeuta Susi Mary de Souza Fernandes, CREFITO: 8144F e R.G. 14.368.741.

São Paulo, 11/ 05 / 2005.

Representante Legal

Para realização do estudo será necessário utilizar alunos da $1^{\mathrm{a}}$ a $4^{\mathrm{a}}$ do ensino fundamental no período da manhã e da tarde, será necessário que a escola providencie junto aos pais ou responsáveis autorização para que seus filhos participem da pesquisa, através de termo de consentimento fornecido pela autora. Mediante autorização dos responsáveis os alunos responderão um questionário, terão suas mochilas pesadas e serão filmados no momento da entrada na escola.

Ainda será necessário que a escola providencie local e agendamento de quatro palestras de orientação em horários e datas diferentes, a primeira para pais de alunos que participarão do estudo, a segunda para professores e direção; a terceira com os alunos participantes. 
Os alunos participantes receberão 3 reforços mensais das orientações ministradas a partir da palestra inicial da autora em conjunto com a professora responsável pela classe durante as aulas.

No final de quatro meses da palestra de orientação com os alunos, será necessário repetir todo processo de avaliação inicial (filmagem, pesagem das mochilas e questionário). 


\title{
Anexo 4: Termo de Consentimento Livre e Esclarecido
}

\author{
HOSPITAL DAS CLÍNICAS
}

DA

FACULDADE DE MEDICINA DA UNIVERSIDADE DE SÃO PAULO

TERMO DE CONSENTIMENTO LIVRE E ESCLARECIDO

\section{I - DADOS DE IDENTIFICAÇÃO DO SUJEITO DA PESQUISA OU RESPONSÁVEL LEGAL}

1. NOME DO PARTICIPANTE :

DOCUMENTO DE IDENTIDADE N ${ }^{\circ}$ : SEXO : $M \quad F$

DATA NASCIMENTO

ENDEREÇO. $\mathrm{N}^{\circ}$ APTO:

BAIRRO:

CEP:. CIDADE TELEFONE: DDD ..)

2.RESPONSÁVEL LEGAL

NATUREZA (grau de parentesco, tutor, curador etc.)

DOCUMENTO DE IDENTIDADE $\mathrm{N}^{\circ}$ : SEXO : $M \quad F$ DATA NASCIMENTO: .......................

ENDEREÇO. $\mathrm{N}^{\circ}$ APTO:

BAIRRO: CIDADE

CEP: TELEFONE: DDD ( ..)

\section{II - DADOS SOBRE A PESQUISA CIENTÍFICA}

1. TÍTULO DO PROTOCOLO DE PESQUISA: Efeitos da orientação postural na utilização de mochilas escolares em estudantes do ensino fundamental.

PESQUISADOR: Susi Mary de Souza Fernandes

CARGO/FUNÇÃO: Fisioterapeuta

INSCRIÇÃO CONSELHO REGIONAL (Crefito-8144F)

2. AVALIAÇÃO DO RISCO DA PESQUISA:

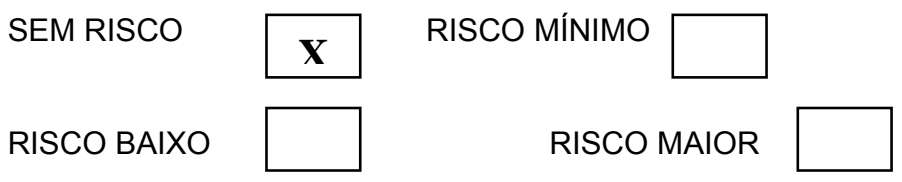

RISCO MÉDIO

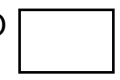

RISCO MAIOR

(probabilidade de que o indivíduo sofra algum dano como consequência imediata ou tardia do estudo) 


\section{DURAÇÃO DA PESQUISA : 06 MESES}

\section{III - REGISTRO DAS EXPLICAÇÕES DO PESQUISADOR AO PACIENTE OU SEU REPRESENTANTE LEGAL SOBRE A PESQUISA CONSIGNANDO:}

1. justificativa e objetivos da pesquisa.

O uso errado de mochilas escolares pode causar problemas de dor nas costas e mudanças na postura das crianças que interferem no desenvolvimento; esse estudo tem como objetivo verificar o tipo, modo de transporte e peso da mochila utilizada pela criança e se existe algum tipo de dor ou alteração na posição das costas entre elas e orientar como devem ser usadas as mochilas de modo correto evitando problemas nas costas.

2. procedimentos que serão utilizados e propósitos, incluindo identificação dos procedimentos que são experimentais.

A criança auxiliada pela professora responderá uma ficha de avaliação inicial onde dados de identificação tais como nome, idade, série que está cursando, tipo de mochila que usa, e se sente algum tipo de dor no corpo serão perguntados, logo abaixo terá um desenho do corpo humano de frente e de costas e a criança que tiver algum tipo de dor marcara no desenho o local onde sente a dor. Em seguida a criança e sua mochila serão pesadas, para relacionarmos o peso do corpo com o peso de material que ela transporta. Para avaliar o modo como transporta a mochila à criança será filmada no momento da chegada a escola. A partir desta avaliação será possível saber se a criança utiliza mochila de modo errado e quais são os erros que precisam ser corrigidos. E então será elaborada palestra de orientação onde à criança receberá explicações sobre modo certo e errado relacionado ao transporte e uso das mochilas escolares. E mensalmente receberá reforço de orientação em sala de aula pelo autor acompanhado da professora responsável pela sala.

Será realizada também palestra de orientações sobre a utilização de mochilas escolares para os pais ou responsáveis, professores e diretores da escola. No final de 6 meses a avaliação inicial será repetida para verificarmos se as orientações resultaram em mudança no modo, peso e tipo de mochila utilizada pela criança.

3. desconfortos e riscos esperados

Não existe nenhum desconforto ou risco, a avaliação e as orientações serão realizadas na própria escola em horários determinados pela direção de modo que não atrapalhem as atividades escolares da criança e sempre serão acompanhados pela professora responsável pela turma; a filmagem será realizada sem que a criança perceba, e as orientações serão baseadas em explicações de movimentos simples que a criança já está acostumada a realizar no seu dia-a-dia.

4. benefícios que poderão ser obtidos

Os resultados do estudo contribuirão para que a criança aprenda a cuidar da suas costas, evitando dores e problemas futuros. Auxiliando no desenvolvimento e na formação de hábitos de saúde. 


\section{IV - ESCLARECIMENTOS DADOS PELO PESQUISADOR SOBRE GARANTIAS DO SUJEITO DA PESQUISA CONSIGNANDO:}

1. acesso, a qualquer tempo, às informações sobre procedimentos, riscos e benefícios relacionados à pesquisa, inclusive para dirimir eventuais dúvidas.

Se os pais ou responsáveis desejarem mais informações sobre este estudo ou surgirem dúvidas, a autora se coloca a disposição para maiores detalhes. Bem como, fica garantido o acesso, a qualquer tempo, às informações sobre procedimentos, riscos e benefícios relacionados à pesquisa.

2. liberdade de retirar seu consentimento a qualquer momento e de deixar de participar do estudo, sem que isto traga nenhum prejuízo ou dano pessoal.

Se os pais ou responsáveis não quiserem mais participar do estudo, tem toda a liberdade de em qualquer momento retirar seu consentimento com a garantia de que não haverá nenhum prejuízo ou cobrança.

3. salvaguarda da confidencialidade, sigilo e privacidade.

É importante dizer que o nome dos pais ou responsáveis, assim como nome e as imagens da criança são confidenciais e não serão expostos em momento algum.

4. disponibilidade de assistência, por eventuais danos à saúde, decorrentes da pesquisa.

Apesar da pesquisa não apresentar riscos, a autora se prontifica a prestar assistência fisioterapêutica, se necessário.

5. viabilidade de indenização por eventuais danos à saúde decorrentes da pesquisa.

A pesquisa não oferece risco algum tendo em vista que os procedimentos baseaiam -se em orientações, sendo assim não há viabilidade de qualquer dano à saúde.

V. INFORMAÇÕES DE NOMES, ENDEREÇOS E TELEFONES DOS RESPONSÁVEIS PELO ACOMPANHAMENTO DA PESQUISA, PARA CONTATO EM CASO DE INTERCORRÊNCIAS CLÍNICAS E REAÇÕES ADVERSAS.

Ft. Susi Mary de Souza Fernandes tel: (11) 96234861

VI - OBSERVAÇÕES COMPLEMENTARES 


\section{VII - CONSENTIMENTO PÓS-ESCLARECIDO}

Declaro que, após convenientemente esclarecido pelo pesquisador e ter entendido o que me foi explicado, consinto em participar do presente Protocolo de Pesquisa

São Paulo, de de 2005. 


\section{Anexo 5: Ficha de avaliação}
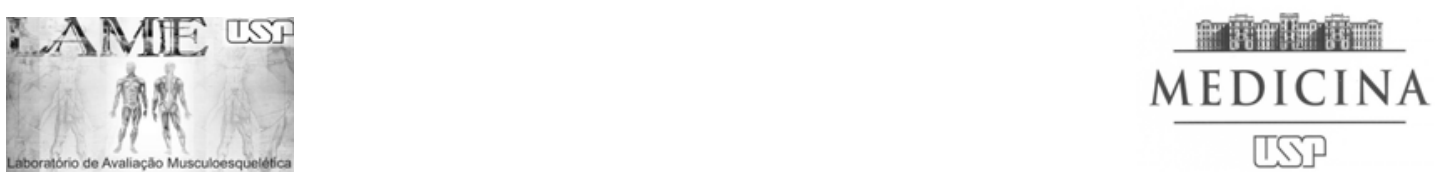

\section{FICHA AVALIAÇÃO}

Data $1^{\mathrm{a}}$ coleta:

Data $2^{\mathrm{a}}$ coleta:

\section{Dados Pessoais}

Nome:

Data de Nascimento:

Sexo:

Série:

Período:

2. Dados Antropométricos do Sujeito

\begin{tabular}{|l|l|l|}
\hline SUJEITO & $1^{\text {a }}$ coleta & $2^{\text {a }}$ coleta \\
\hline PESO & & \\
\hline ALTURA & & \\
\hline
\end{tabular}

3. Dados Equipamento

\begin{tabular}{|c|c|c|}
\hline MOCHILA & $\mathbf{1}^{\text {a }}$ coleta & $\mathbf{2}^{\text {a coleta }}$ \\
\hline TIPO & & \\
\hline PESO & & \\
\hline
\end{tabular}

LEGENDA: Tipo de mochila (TM): 1 alça (1); 2 alças (2); Carrinho (3) 
5. Modo de Transporte da mochila :

\begin{tabular}{|c|c|c|c|c|}
\hline $\begin{array}{c}\text { Modo de } \\
\text { transporte (MT) }\end{array}$ & 5 & 6 & 7 & 8 \\
\hline $1^{\text {a }}$ coleta & & & & \\
\hline $2^{\text {a coleta }}$ & & & & \\
\hline
\end{tabular}

LEGENDA: Tipo de mochila (TM): 1 alça (1); 2 alças (2); Carrinho (3) Modo de transporte (MT): transporte ombro unilateral(5), ombro bilateral(6), mãos(7) e mãos no modelo carrinho(8) 
Anexo 6: Folheto de orientações aos pais ou responsáveis
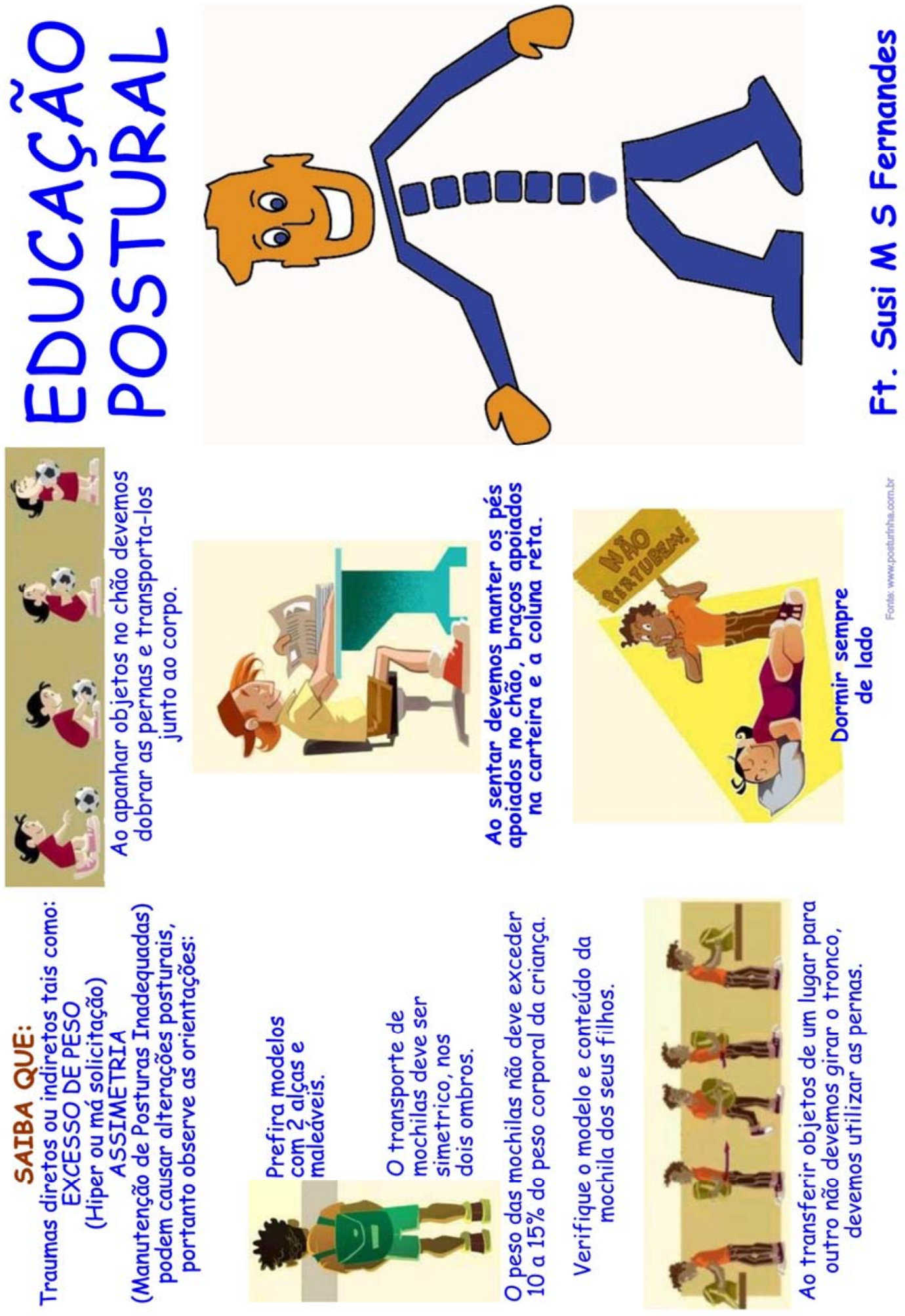

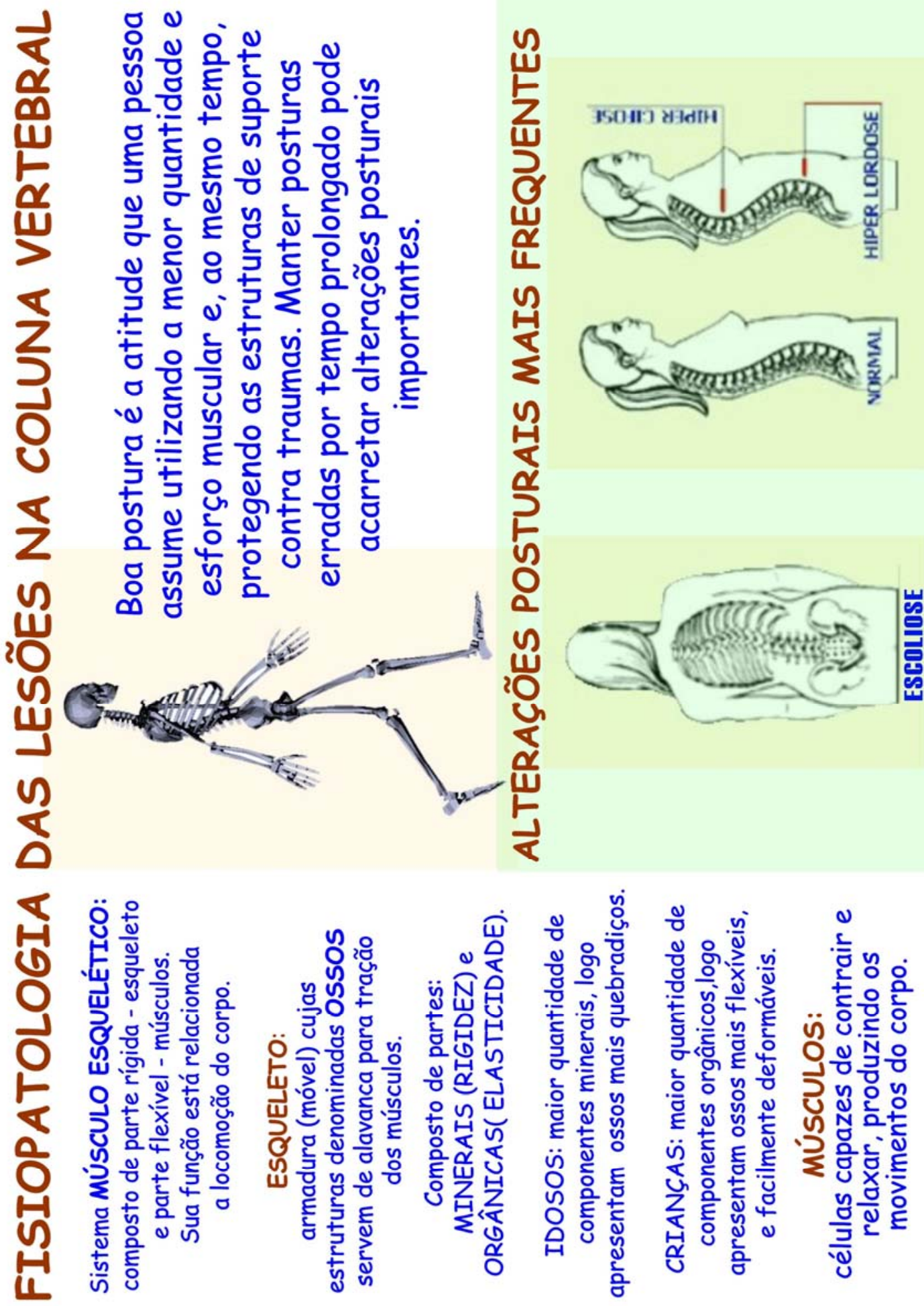
8. REFERÊNCIAS 
Andrade SC, Araujo AGR, Vilar MJP. "Back School”: Historical Revision and Its Application in Chronic Low Back Pain. Rev Bras Reumatol. 2005; 45(4): 224-8.

Balague F, Nordin M, Dutoit G, Waldburger M. Primary prevention, education, and low back pain among school children. Bull Hosp J Dis.1996;55(3):130-4.

Balague F, Troussier B, Salminen JJ. Non-specific low back pain in children and adolescents: risk factors. Eur Spine J. 1999;8(6):429-38.

Brattberg G. The incidence of back pain and headache among Swedish school children. Qual Life Res. 1994;3:S27-31.

Burton AK, Waddell G, Tillotson KM, Summerton N. Information and advice to patients with back pain can have a positive effect. A randomized controlled trial of a novel educational booklet in primary care. Spine.1999;24(23):2484-91.

Burton AK, How to prevent low back pain. Best Practice \& Research Clinical Rheumatology. 2005; 19(4):541-55.

Cardon G, De Bourdeaudhuij I, De Clercq D. Generalization of back education principles by elementary school children: evaluation with a practical test and a candid camera observation. Acta Paediatr. 2001a;90(2):143-50.

Cardon G, De Bourdeaudhuij I, De Clercq D. Back care education in elementary school: a pilot study investigating the complementary role of the class teacher. Patient Educ Couns. 2001b;45(3):219-26. 
Cardon GM, De Clercq DL, De Bourdeaudhuij IM. Back education efficacy in elementary schoolchildren: a 1-year follow-up study. Spine. 2002a ;1;27(3):299-305.

Cardon G, De Bourdeaudhuij I, De Clercq D. Knowledge and perceptions about back education among elementary school students, teachers, and parents in Belgium. Sch Health. 2002b ;72(3):100-6.

Chansirinukor W, Wilson D, Grimmer K, Dansie B. Effects of backpacks on students: measurement of cervical and shoulder posture. Aust $J$ Physiother. 2001;47(2):110-6.

Conover WU. Pratical Nonparametric Statistics. Jonh Willy \& Sons. New York: 1971.

Cottalorda J, Bourelle s, Gautheron V, Kohler R. Backpack and spinal disease: myth or reality? Chir Orthop Reparatrice Appar Mot. 2004;90(3):207-14.

European Guidelines For Prevention In Low Back Pain. Nov 2004; disponível www.backpaineurope.org

Feingold AJ, Jacobs K. The effect of education on backpack wearing and posture in a middle school population.Work. 2002; 18(3):287-94.

Geldhof E, Cardon G, De Bourdeaudhuij I, De Clercq D. Back posture education in elementary schoolchildren: a 2 -year follow-up study. Eur Spine J. 2007; 16(6): 841-50.

Goodgold S, Corcoran M, Gamache D, Gillis J,Guerin J, Coyle JQ. Backpack use in children. Pediatr Phys Ther. 2002; 14(3):122-31.

Goodgold SA, Nielsen D. Effectiveness of a school-based backpack health promotion program: Backpack intelligence. Work. 2003; 21(2):113-23. 
Harreby M, Kjer J, Hesselsoe G, Neergaard K. Epidemiological aspects and risk factors for low back pain in 38-year-old men and women: a 25-year prospective cohort study of 640 school children. Eur Spine J. 1996;5(5):312-8.

Heymans M, Tulder M, Esmail R, Bombardier C, Koes B. Back Schools for non specific low-back pain. Cochrane Database Syst Rev. 2004; 18(4):CD000261.

Kristjansdottir G, Rhee H. Risk factors of back pain frequency in schoolchildren: search for explanations to a public health problem. Acta Paediatr. 2002; 91(7): 849-54.

Korovessis P, Koureas G, Papazisis Z. Correlation between backpack weight and way of carrying, sagittal and frontal spinal curvatures, athletic activity, and dorsal and low back pain in schoolchildren and adolescents. Spinal Disord Tech. 2004;17(1):33-40.

Leboeuf-Yde C, Kyvik Ko, Bruun NH. Low back pain and lifestyle. Part II-Obesity. Information from a population-based sample of 29,424 twin subjects. Spine. 1999;15;24(8):779-83.

Limon S, Valinsky LJ, Ben-Shalom Y. Children at risk: risk factors for low back pain in the elementary school environment. Spine. 2004 ;1;29(6):697-702.

Mackie HW, Legg SJ, Beadle J, Hedderley D. Comparison of four different backpacks intended for school use. Appl Ergon. 2003;34(3):257-64.

Mackie HW, Stevenson JM, Reid SA, Legg SJ. The effect of simulated school load carriage configurations on shoulder strap tension forces and shoulder interface pressure. Appl Ergon. 2005;36(2):199-206.

Maier - Reihle B, Harter M. The effects of back school - meta-analysis. Int $J$ Rehabil Res. 2001; 24: 199-206. 
Mason DE. Back pain in children. Pediatr Ann. 1999;28(12):727-38.

Mendez FJ, Gomez-Conesa A. Postural hygiene program to prevent low back pain. Spine. 2001; 1;26(11):1280-6.

Ministério da Saúde, Brasil. Secretaria de Políticas de Saúde. A promoção da saúde no contexto escolar. Rev. Saúde Pública. 2002; 36 (4):533-35.

Mirovsky Y, Jakim I, Halperin N, Lev L. Non-specific back pain in children and adolescents: a prospective study until maturity. J Pediatr Orthop B. 2002;11(4):275-8.

Negrini S, Carabalona R. Backpacks on! Schoolchildren's perceptions of load, associations with back pain and factors determining the load. Spine. 2002; 15;27(2):187-95.

Negrini S, Politano E, Carabalona R, Tartarotti L, Marchetti ML. The backpack load in schoolchildren: clinical and social importance, and efficacy of a community-based educational intervention. A prospective controlled cohort study. J Eura Medicophys. 2004;40(3):185-90.

Newcomer K, Sinak I M, Wollan PC. Physical activity and four-year development of back strength in children. Am J Phys Med Rehabil. 1997;76(1):52-8.

Pascoe DD, Pascoe DE, Wang YT, Shim DM, Kim CK. Influence of carrying book bags on gait cycle and posture of youths. Ergonomics. 1997;40(6):631-41.

Rateau MR. Use of backpacks in children and adolescents. A potential contributor of back pain. Orthop Nurs. 2004;23(2):101-5.

Robertson HC, Lee V. Effects of back care lessons on sitting and lifting by primary stundents. Aust J Physiother. 1990; 36(4):245-48. 
Roth-Isigkeit A, Thyen U, Raspe HH, Stöven H, Schmucker P. Reports of pain among German children and adolescents: an epidemiological study. Acta Paediatr. 2004;93(2):258-63.

Siambanes D, Martinez JW, Butler EW, Haider T. Influence of school backpacks on adolescent back pain. J Pediatr Orthop. 2004; 24(2):211-7.

Sheir-Neiss GI, Kruse RW, Rahman T, Jacobson LP, Pelli JA. The association of backpack use and back pain in adolescents. Spine. 2003;1;28(9):922-30.

Skaggs DL, Early SD, D'Ambra P, Tolo VT, Kay RM. Back pain and backpacks in school children. J Pediatr Orthop. 2006;26(3):358-63.

Slawta J, Bentley J, Smith J, Kelly J, Syman-Degler L. Promoting Healthy Lifestyles in Children: A Pilot Program of Be a Fit Kid. Health Promotion Practice - Society for Public Health Education. 2006, 10:11.

Taimela S, Kujala UL, Salminen JJ, Viljanen T. The prevalence of low back pain among children and adolescentes. A nationwide cohort -based questionnaire survey in Finland. Spine. 1997; 22(10):1132 -36.

Troussier B, Marchou-Lopez S, Pironneau S, Alais E, Grison J, Prel G, Pequegnot C, Degaudemaris R, Phelip X. Back pain and spinal alignment abnormalities in schoolchildren. Rev Rhum Engl Ed. 1999;66(7-9):370-80.

Watson KD, Papageorgiou AC, Jones GT, Taylor S, Symmons DPM, Silman AJ, Macfarlane GJ. Low back pain in schoolchildren: the role of mechanical and psychosocial factors. Arch Dis Child. 2003; 88: 12-17.

Vieira S. Bio Estatística Tópicos Avançados. Editora Campus, 2ª Edição. Rio de Janeiro; 2004. 
Viry P, Creveuil C, Marcelli C. Nonspecific back pain in children. A search for associated factors in 14-year-old schoolchildren. Rev Rhum Engl Ed. 1999;66 (7-9):381-8.

Zapater AR, Silveira DM, Vitta A , Padovani CR, Silva JCP. Seat posture: the efficiency of an educational program for scholars. Ciênc Saúde Coletiva. 2004;9(1):191-99 